Peter Scherrer

\title{
Von Apaša nach Hagios Theologos Die Siedlungsgeschichte des Raumes Ephesos von prähistorischer bis in byzantinische Zeit
unter dem Aspekt der maritimen und fluvialen Bedingungen
}

\section{Einleitung}

Das Ruinenfeld der antiken Großstadt Ephesos* liegt im Gemeindegebiet der modernen Bezirksstadt Selçuk an der Ostküste der Ägäis ungefähr 70 Straßenkilometer südlich von Izmir, dem antiken Smyrna, das einst die große Rivalin von Ephesos im Kampf um die Stellung als wichtigster Hafenplatz Westkleinasiens war. Die wirtschaftliche Bedeutung von Ephesos und der hier angesammelte Reichtum beruhten auf seinem Hafen, der als Asylplatz einer großen, später Artemis Ephesia genannten Göttin begonnen hatte und über mehr als 1000 Jahre - vom Achämenidenreich bis mindestens zur Gründung von Konstantinopel als neuer (ost-)römischer Hauptstadt - der wichtigste Umschlag- und Verladeplatz für Waren der als >Königsstraße< oder >Seidenstraße< bekannten Karawanenroute aus Zentralasien zum Weitertransport zur See in den gesamten Mittelmeerraum und vice versa war.

Die historischen Siedlungen der vergangenen 7000 Jahre im Raum Ephesos befinden sich sämtlich an der Südseite einer seit dem Mittelalter endgültig verlandeten Bucht von etwa $8 \mathrm{~km}$ Tiefe, in welcher der heute Küçük Menderes, im Altertum Kaystros genannte Fluss in das Meer mündet (Abb. 1). Gerade noch in Sichtweite liegt knapp vor der $25 \mathrm{~km}$ südlich von Ephesos mit dem Mykalegebirge weit nach Westen vorspringenden Küste die Insel Samos. An der Biegung dieser Küste lag in griechischer Zeit, mit über $30 \mathrm{~km}$ Abstand eine anstrengende Tagesreise von Ephesos entfernt, das Panionion, das kultische Zentrum des Ionischen Bundes, dem Ephesos nach Herodot und Strabon angehörte ${ }^{1}$. Bis hierher am Fuß der Mykale erstreckte sich nach Strabon seit der Zerstörung der Stadt Melie um 700 v. Chr. das Territorium von Ephe$\operatorname{sos}^{2}$. Auf halbem Weg lag der Ort Pygela, ein von den Genuesen im späten Mittelalter unter dem Namen Scala Nuova besetzter Hafen, der heute als Ferienort Kuşadası große Bedeutung besitzt. Irgendwo zwischen Pygela und Ephesos öffnete sich das Tal von Ortygia zum Meer, wo Leto nach dem Lokalmythos einst Apollon und Artemis, die Schutzgöttin der Stadt, geboren haben soll. Der von Strabon ${ }^{3}$ geschilderte und von Tacitus hervorgehobene heilige Hain mit Tempelanlagen und Speisehäusern ${ }^{4}$ am bemerkenswerten ${ }^{5}$ Fluss Kenchrios, wo die Ephesier alljährlich nach großer Prozession die Geburt ihrer Göttin feierten und das Kollegium der Kureten heilige Rituale vollzog, ist leider bis heute nicht gefunden worden ${ }^{6}$.

* Für vielfältige Unterstützung und die Möglichkeit der Verwendung von ihm in Auftrag gegebener Bildunterlagen danke ich dem ehemaligen Direktor des Österreichischen Archäologischen Instituts und Leiter der Ausgrabungen Ephesos, Friedrich Krinzinger, ferner danke ich John Chris Kraft, Helmut Brückner und dem Institutsphotographen Nikolas Gail. - Vorliegender Aufsatz ist die überarbeitete Fassung eines am 20. 11. 2004 in Paris beim Internationalen Symposium »Villes fluviales et maritimes: les contraintes de l'environnement« gehaltenen Vortrags und Bestandteil meiner Habilitationsschrift, die 2005 von der Universität Salzburg angenommen wurde. Die hier zusätzlich zu den vom ÖAI < http://www.oeai.at/publik/autoren.hml> empfohlenen Kurzzitate finden sich am Ende des Beitrags.

${ }^{1}$ Hdt. 1, 147-148; Strab. 14, 3-4.

2 Strab. 14, 20.

${ }^{3}$ Strab. 14, 20.

4 Tac. ann. 3, 61 .

5 Paus. 7, 5, 10.

${ }^{6} \mathrm{Zu}$ den Lokalisierungsversuchen vgl. J. Keil, Ortygia, die Geburtsstätte der ephesischen Artemis, ÖJh 20/21, 1922-1924, 113-119. Keils Zuweisung scheitert daran, dass er den Fluss Kenchrios mit dem Değirmen çay, also jenem Wasserlauf gleich- 


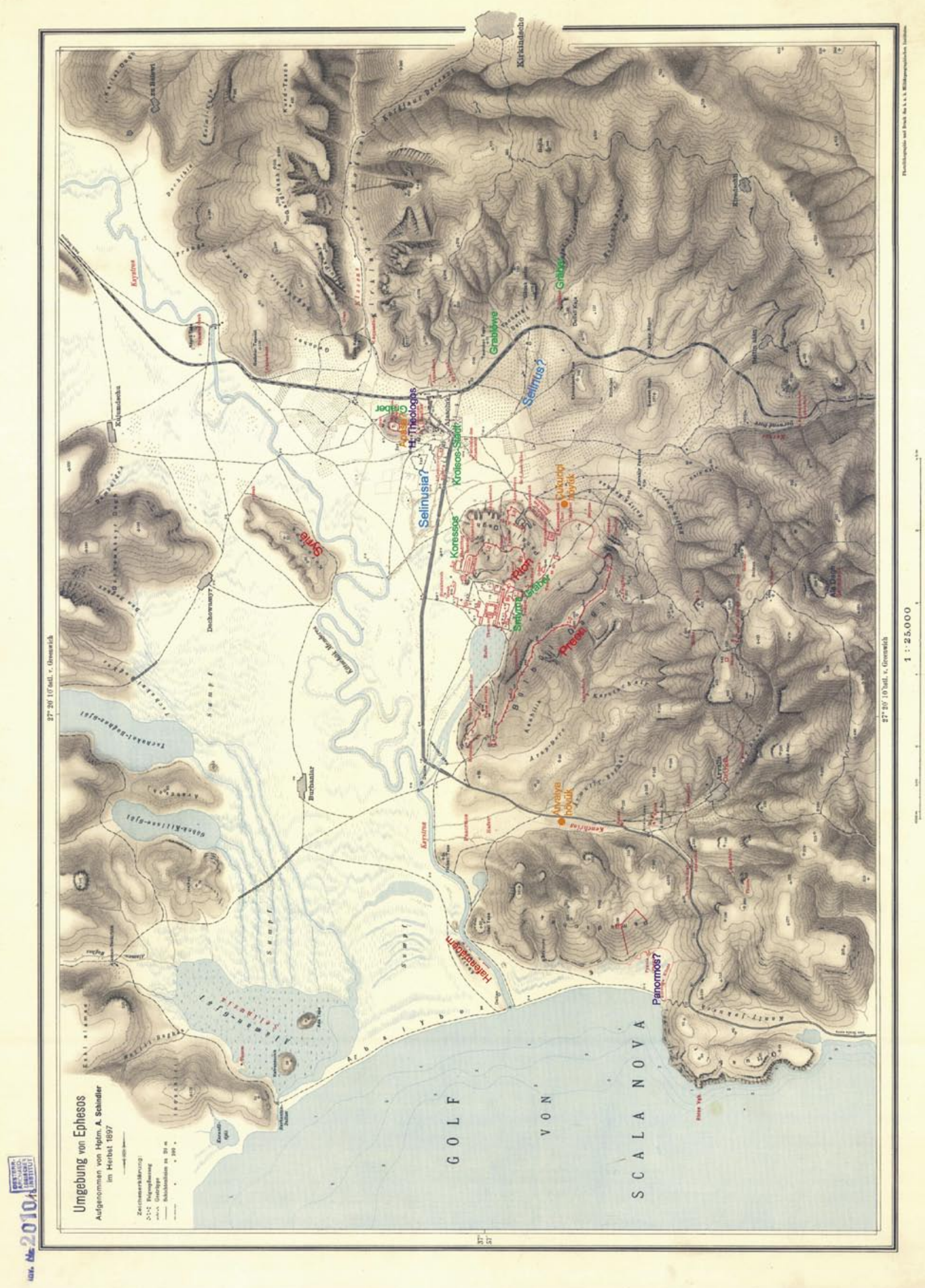


Dafür ist nach langjähriger intensiver Suche des britischen Eisenbahningenieurs J. T. Wood seit dem Silvestertag 1869 die Lage des Artemistempels bekannt ${ }^{7}$, der in der Antike als sechstes der >sieben Weltwunder in entsprechenden Listen geführt worden war $^{8}$ (Abb. 7). Wood fand dessen Marmorfundament in einer Tiefe von $20 \mathrm{Fuß}$, also $6 \mathrm{~m}$, unter der rezenten Oberfläche, nachdem er sich mühsam durch das oberflächlich immer gut erkennbare Ruinenfeld der hellenistisch-römischen Stadt zum `Magnesischen Tor` und von dort entlang einer Straße durch das Schwemmland der Ebene gegraben hatte.

Damit sind die beiden Hauptschwierigkeiten bei der Erforschung von Ephesos angesprochen. Zuerst ist die über Jahrtausende sukzessiv erfolgte starke Veränderung der topographischen Situation zu erwähnen. Nach geologisch-küstengeographischen Untersuchungen kam es im Mittelmeerraum etwa vom 16. bis zum 6. Jahrtausend v. Chr. zu einem langsamen Anstieg des Wasserstandes um insgesamt ca. 120-130 m in etwa auf das heutige Niveau. Im 4. Jahrtausend v. Chr. sank der Meeresspiegel wiederum um ungefähr $2 \mathrm{~m}$, um anschließend wieder langsam anzusteigen ${ }^{9}$. Dadurch wurden - nicht nur an der Küste Kleinasiens - die Flüsse gebremst und daran gehindert, die mitgebrachten Feststoffe in das offene Meer hinauszuführen. Es entstand ein Wechselspiel der Kräfte, bei dem antike Siedlungen vom ansteigenden Meer überflutet oder durch die Ablagerung der Flüsse von diesem abgeschnitten und manchmal auch in ihren tieferen Teilen meterhoch überdeckt oder vom Grundwasser überschwemmt werden konnten. Darüber hinaus haben klimatische Faktoren, Erdbeben, Überschwemmungen und vor allem auch menschliches Handeln wie die Jahrhunderte währende rücksichtslose Abholzung zur Erosion der Oberfläche und anderen starken Veränderungen der Landschaft beigetragen. Als Antwort auf diese Veränderungen der Umwelt - und darin liegt das zweite Hauptproblem der Ephesosforschung - mussten die direkt am Meer oder an Flüssen nahe deren Mündung gelegenen Siedlungsstellen immer wieder verlegt werden, um entweder nicht physisch - im ursprünglichsten Sinne des Wortes - unterzugehen oder zumindest nicht die Vorteile der Hafenlage zu verlieren.

\section{Von Apaša nach Ephesos: Die historischen Siedlungsstellen in der ephesischen Bucht von der Bron- zezeit bis zum Ende der klassischen Epoche}

In der ephesischen Bucht sind an mehreren Stellen Streufunde des späten Chalkolithikums (5. und 4. Jahrtausend v. Chr.) aufgesammelt worden, aber nur zwei frühe Siedlungsplätze wurden im Jahr 1995 wenigstens peripher untersucht ${ }^{10}$. Der Çukuriçi Höyük (Abb. 1-3) liegt am westlichen Rand der schon damals als Kulturland nutzbaren Mündungsebene des Dervend Dere oberhalb von dessen linkem Ufer, ca. $500 \mathrm{~m}$ vom Magnesischen Tor der hellenistisch-römischen Stadt in ungefähr östlicher Richtung entfernt. Bei der archäologischen Untersuchung durch das Efes Müzesi Selçuk wurden neben Werkzeugen aus Obsidian und Silex auch zahlreiche, teilweise schwarz gefirnisste Keramikgefäßfragmente geborgen. Diese und ein Beil aus Bronze ergeben eine Datierung der Siedlung in das 3. Jahrtausend v. Chr., also in das späteste Chalkolithikum oder die Frühbronzezeit. Der zweite Siedlungsplatz liegt in dem Nord-Süd gerichteten, heute Arvalya genannten Tal an der Westseite des Bülbüldağ (Abb. 1. 3) und wurde deshalb als Arvalya Höyük bezeichnet. Einige wenige Keramikfragmente, dabei ein gelochter vertikaler Henkel einer Schale, Steinbeile und verschiedene Silex- und Obsidiangeräte erlauben ebenfalls eine vorläufige Datierung in das 3. Jahrtausend v. Chr.

setzt, von dem wir heute annehmen dürfen, dass er in antiker Zeit den Namen Marnas getragen hat (vgl. dazu u. bei Anm. 140-142). Der ältere, schon von Benndorf, Ortskunde, 76-78, mit weiteren Argumenten gestützte Ansatz im heute Arvalya genannten Tal westlich des Bülbüldağ, dem die meisten Forscher/-innen bis heute folgen, leidet darunter, dass hier überhaupt kein erwähnenswerter Wasserlauf, sondern nur ein Bächlein durchfließt.

7 J. T. Wood, Discoveries in Ephesus (London 1877) 155.

${ }^{8}$ Bammer - Muss, Artemision 10.

${ }_{9}$ Kraft u. a., Analysis, bes. $178 \mathrm{f}$.

${ }^{10}$ A. Evren - C. İçten, Efes Çukuriçi ve Arvalya (Gül Hanım) höyükleri, in: 8. Müze Kutarma Kazıları Semineri (Ankara 1997) 111-133. - 2006 wurden von B. Horejs systematische Grabungen auf dem Çukuriçi Höyük begonnen; s. dazu in vorliegendem Band den Jahresbericht des Österreichischen Archäologischen Instituts 2006, $413 \mathrm{f}$. sowie $<$ http://www.oeai.at/ausland/cukurici.html> (Befunde aus dem frühen und späten Chalkolithikum). 


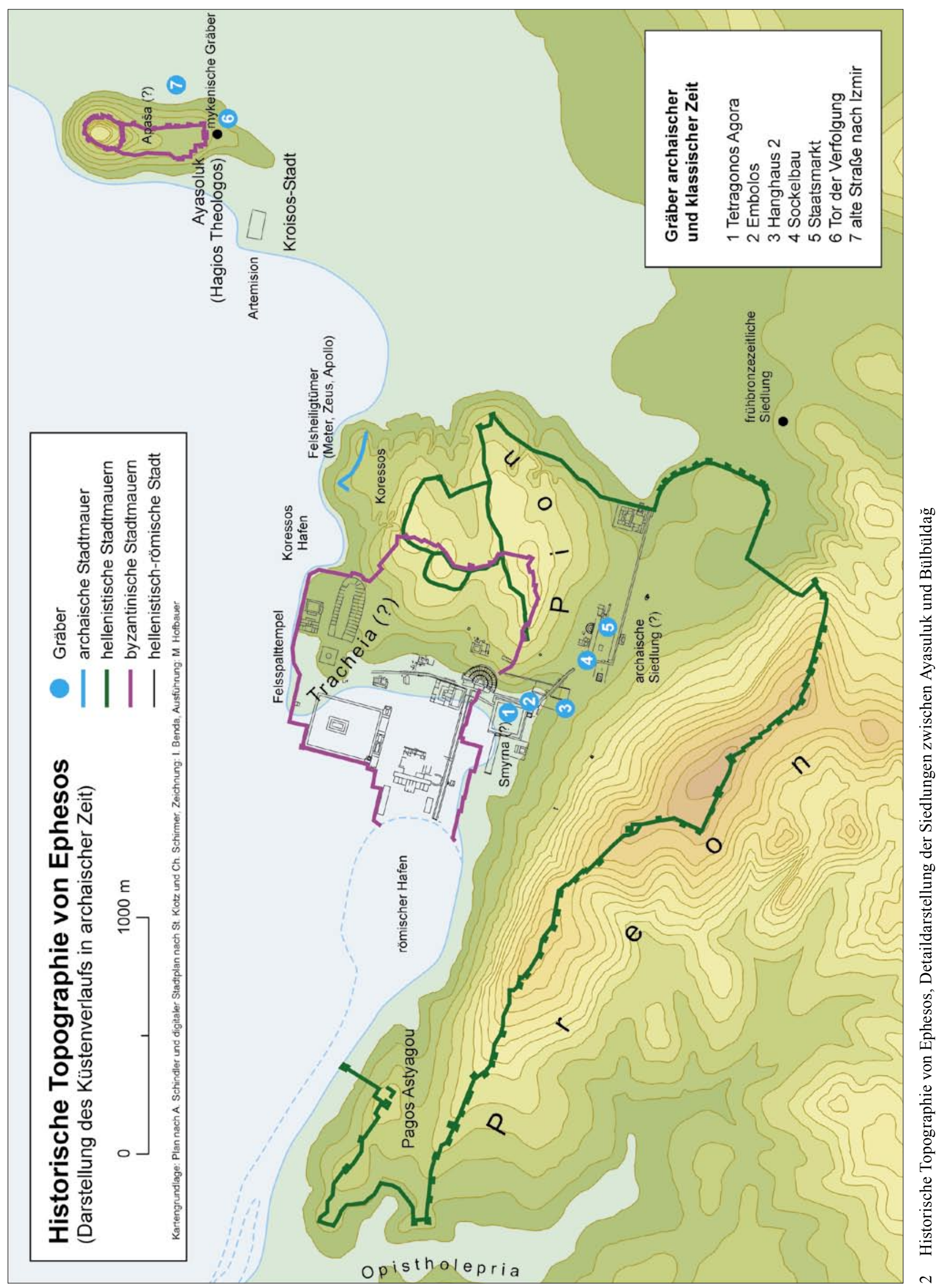


Der bedeutendste Siedlungsplatz der Region lag aber schon damals wohl am Ayasuluk an der Ostseite der ephesischen Bucht (Abb. 1-7). Die Funde aus den seit 1990 von M. Büyükkolancı auf der Kuppe des Hügels durchgeführten Ausgrabungen ${ }^{11}$ sind noch nicht endgültig aufgearbeitet, reichen aber kontinuierlich vom 3. Jahrtausend bis in die spätmykenische Zeit und setzen im 11. Jahrhundert v. Chr. erneut ein ${ }^{12}$. Vorläufig lässt sich zumindest konstatieren, dass hier seit dem frühen 3. Jahrtausend eine Zentralsiedlung bestand, die heute mit einiger Sicherheit als das vom Hethiterkönig Mursili II im 14. Jahrhundert v. Chr. eingenommene Apaša, die Hauptstadt des Reiches von Arzawa ${ }^{13}$, identifiziert werden darf ${ }^{14}$. Das Keramikspektrum des 2. Jahrtausends ist von anatolischen Elementen geprägt, es muss aber, wie auch mykenische Importe (LH III A ${ }^{2}$ : 14. Jh. v. Chr.) in einem in lokaler Tradition stehenden $\mathrm{Grab}^{15}$ beweisen, zumindest intensive Handelskontakte mit der mykenischen Kultur oder gar ein mykenisches Emporion gegeben haben. Ein Stück einer Quadermauer wurde vom Ausgräber vorläufig in das 2. Jahrtausend v. Chr. datiert und als Festungsmauer von Apaša bezeichnet ${ }^{16}$.

Vor dem Ayasuluk an der einstigen Küste liegt das weltberühmte Heiligtum der Artemis Ephesia (Abb. 2. 3. 7). Nach neuesten Erkenntnissen wurde der Platz zumindest seit mykenischer Zeit intensiv begangen und diente seit der zweiten Hälfte des 11. Jahrhunderts v. Chr. als sakraler Bezirk ${ }^{17}$.

S. Morris hat jüngst in einer anregenden Studie herausgearbeitet, dass die Göttin nicht, wie bisher gerne angenommen, eine Muttergottheit, sondern die Stadt- und Schutzgöttin von Apaša gewesen sein dürfte und mit der in Linear-B-Texten aus Pylos genannten Potnia Aswiya identifiziert werden darf ${ }^{18}$. Dazu würde passen, dass Artemis noch in der hohen römischen Kaiserzeit als »Herrin der Stadt« bezeichnet wurde ${ }^{19}$. Auch eine bereits früher geäußerte Vermutung von St. Karwiese ${ }^{20}$ deutet in diese Richtung; er stellte das lateinische Lehnwort apis mit Apaša und Ephesos bzw. Ephesia zusammen und gab damit der Göttin den Namen 〉Bienenkönigin<, wie ja auch ihre obersten Priester noch in der hellenistisch-römischen Zeit

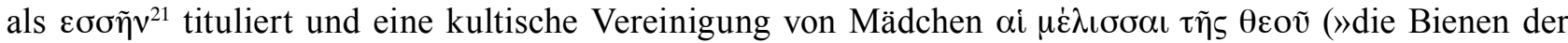
Göttin«) genannt wurden ${ }^{22}$.

Wenn Artemis Ephesia tatsächlich die Nachfolgerin der alten Stadtgöttin von Apaša war, stellt sich die Frage, wo sich das Heiligtum des 3. und 2. Jahrtausends v. Chr. befunden haben könnte: Am ehesten wäre es wohl in der Stadt selbst, also auf dem Ayasuluk, zu suchen. Wie aber kam dann die Göttin an ihren späteren Platz an der Küste?

${ }^{11}$ Vorläufige Berichte: S. Erdemgil - M. Büyükkolanc1, Jüngste archäologische Nachweise für die älteste Geschichte von Ephesos, in: F. Hueber, Ephesos. Gebaute Geschichte, Sonderh. AW 28 (Mainz 1997) 26-28; S. Erdemgil - M. Büyükkolanc1, 1990 yılı Efes-Ayasuluk tepesi prehistorik kazıs1, KST 13, 1992, 265-281; M. Büyükkolanc1, Ayasuluk tepesi (eski Efes) 1996 yılı kazıları, in: 8. Müze Kutarma Kazıları Semineri (Ankara 1998) 69-83; Büyükkolancı, Excavations. Außerdem M. Büyükkolancı, Prähistorische Untersuchungen in der Umgebung von Ephesos (1990-1997), in: Forum Archaeologiae $7 /$ VI/1998 < http://farch.net>; M. Büyükkolanc1, Excavation on Ayasuluk Hill, Selçuk/Turkey, Forum Archaeologiae 10/III/99 $<$ http://farch.net>.

12 Vgl. vorläufig: Kerschner, Wanderung, bes. 366-368.

${ }_{13}$ S. Heinhold-Krahmer, Arzawa, Texte der Hethiter 8 (Heidelberg 1977) 93-95.

${ }^{14}$ J. Garstang - O. R. Gurney, The Geography of the Hittite Empire (London 1959) 84 und 88 f.; zur weitgehenden Akzeptanz dieser Identifikation in der neueren Lit. vgl. Kerschner, Wanderung, 368 f. mit Anm. 42.

${ }_{15}$ H. Gültekin - M. Baran, The Mycenaean Grave Found at the Hill of Ayasuluk, TAD 13/2, 1964, 125-133.

${ }^{16}$ Büyükkolanc1, Excavations 39 und Abb. 12; Ch. Mee, Anatolia and the Aegean in the Late Bronze Age, in: E. H. Cline D. Harris-Cline (Hrsg.), The Aegean and the Orient in the Second Millennium, Proceedings of the 50th Anniversary Symposium Cincinnati, 18-20 April 1997 (Eupen 1998) 139 f.

${ }_{17}$ U. Muss, Vom Mythos zur Archäologie eines Heiligtums: Ein bronzezeitlicher Kopf aus dem Artemision, in: Muss, Kosmos, 153-168; Kerschner, Wanderung 369-373.

${ }_{18}$ S. P. Morris, The Prehistoric Background of Artemis Ephesia: A Solution to the Enigma of >Her Breasts`, in: Muss, Kosmos 135-150; S. P. Morris, Potnia Aswiya: Anatolian Contributions to Greek Religion, in: R. Laffineur -R. Hägg (Hrsg.), Potnia: Deities and Religion in the Aegean Bronze Age. Proceedings of the $8^{\text {th }}$ International Aegean Conference Göteborg, Göteborg University, 12-15 April 2000, Aegeum 22, 2001, 423-434.

${ }_{19} \mathrm{Vgl}$. z. B. IvE 3263 mit einem Neopoios $\tau \tilde{\eta} \varsigma$ $x v \varrho i \alpha \varsigma \eta \mu \tilde{v}$.

${ }^{20}$ Karwiese, Artemis 14.

${ }^{21}$ Paus. 8, 13, 1 erklärt das Wort als »Bienenkönig«.

${ }^{22}$ IvE 2109; allgemein zu den Melissa genannten Priesterinnen vgl. K. v. Fritz in: RE XV 1 (1931) 524-528, bes. 526 (s. v. Melissa). Außerdem ist um 100 n. Chr. der Frauenname Melissa im ephesischen Großbürgertum belegt, anscheinend ein auf den Tempeldienst bezogener Priesterinnenname: IvE 508. 


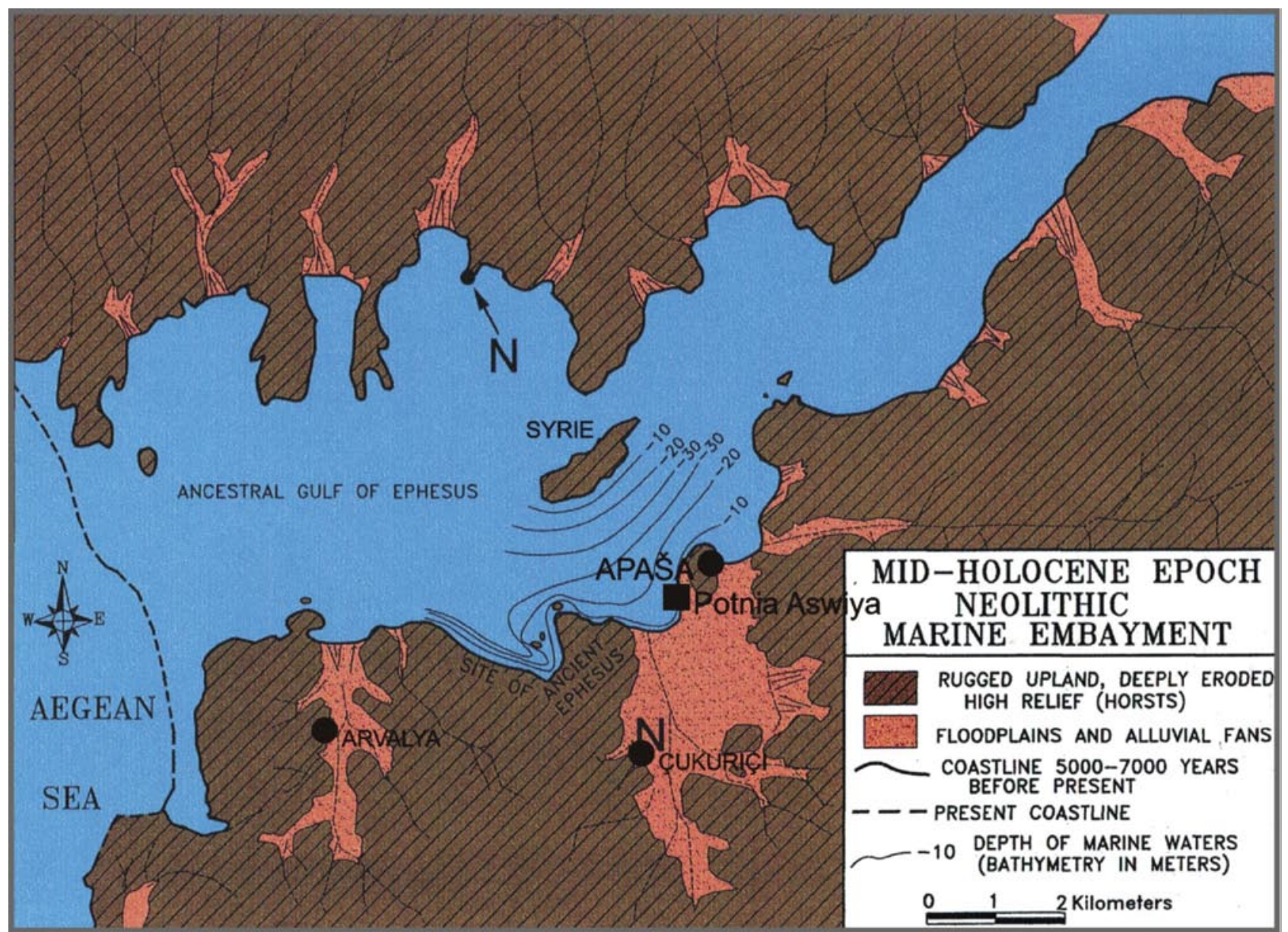

3 Küstenverlauf in der ephesischen Bucht in der Bronzezeit, ca. 2. Jtsd. v. Chr.

Nach gängiger Meinung bestand die ursprüngliche Bedeutung des Kultplatzes der Artemis von Ephesos in einem Asylon an einem Hafen, der ohne Gefährdung allen Händlern und Reisenden offenstand und neben dem sicheren Ankerplatz auch frisches Wasser und die Möglichkeit des Warenaustausches bot ${ }^{23}$. Dieser Hafen und der Kultplatz als eine Filiale des Tempels auf dem Stadtberg müssten sodann schon in luwischer Zeit bestanden haben ${ }^{24}$ und nach dem Untergang von Mykene und Apaša durch die Einwanderer der frühen Eisenzeit auf Grundlage der zweifellos vorhandenen Erinnerungen an die Orte der mykenischen Zeit wiederbelebt worden sein. Eine bauliche Ausgestaltung des Kultplatzes fand allerdings anscheinend erst frühestens ab der Mitte des 9. Jahrhunderts v. Chr. statt ${ }^{25}$, wobei die Ausgestaltung mit Kleinbauten, Altären oder Baldachinen für ein Kultbild begann und mit einer sich in den Dimensionen steigernden Reihe von Ringhallentempeln fortgesetzt wurde. Funktion und Datierung in das 8. Jahrhundert eines von den Ausgräbern als »ältester griechischer Ringhallentempel« bezeichneten Bauwerks ${ }^{26}$ als Vorgänger des sog. Tempels C (erste Hälfte 6. Jh. n. Chr.) und schlussendlich des berühmten Kroisostempels sind allerdings

${ }^{23}$ Zum Asylon und der Bedeutung der Wollbinden der Artemisstatuen als an die Gottheit übergebene Symbole der Schutzflehenden vgl. nun R. Fleischer, Die Amazonen und das Asyl des Artemisions von Ephesos, JdI 117, 2002, $185-216$.

${ }^{24} \mathrm{Zu}$ plausiblen Gegentheorien, dass nämlich analog zu westgriechischen Kolonien das ephesische Heiligtum ohne Rücksicht auf einen einheimischen Kultplatz von den einwandernden Griechen als extra-urbaner Sakralbezirk angelegt worden sein könnte, vgl. Brenk, Artemis bes. 161-164.

${ }^{25}$ Kerschner, Wanderung, bes. 369; Weiß1, Grundzüge, bes. 329-331.

${ }^{26} \mathrm{Zu}$ den Bauten vor Kroisos etwa: A. Bammer, A Peripteros of the Geometric Period in the Artemision of Ephesus, AnSt 40, 1990, 137-160; A. Bammer, Les sanctuaires archaiques de l'Artémision d'Ephèse, in: R. Étienne - M. Th. Le Dinahet (Hrsg.), L'espace sacrificiel dans les civilisations méditerranéennes de l'antiquité. Actes du Colloque tenu à Maison de l'Orient, Lyon, 
auf teils heftigen Widerspruch gestoßen ${ }^{27}$. Unabhängig von den vielen in Diskussion befindlichen Fragen und den großen Lücken in den archäologischen Befunden, denen nachzugehen hier nicht der Ort ist, steht eindeutig fest, dass der Kultplatz der Artemis Ephesia vom mittleren oder ausgehenden 11. Jahrhundert v. Chr. bis zur Auslöschung des Kultes um 400 n. Chr. in zahlreichen Bauphasen des Haupttempels und mit der zusätzlichen Errichtung von vielen weiteren Gebäuden im Areal des Heiligtums unverändert Bestand hatte, auch als das Meer bereits weit zurückgewichen und das Heiligtum allseitig von bebaubarem Land umgeben war.

Noch haben wir nur wenig mehr als eine Ahnung von den Siedlungsstrukturen in der Nähe des Artemisheiligtums. Auf der Höhe des Ayasuluk setzen nach einem Hiatus von einem Vierteljahrtausend um 1050 v. Chr. die Keramikfunde im ehemaligen bronzezeitlichen Siedlungsbereich wieder ein, brechen aber im 6. Jahrhundert v. Chr. weitgehend ab. M. Büyükkolancı schlug deshalb jüngst in Wiederaufnahme älterer ähnlicher Meinungen vor, hier die vom sagenhaften athenischen Königssohn Androklos gegründete und nach einer Belagerung durch König Kroisos aufgegebene griechische Ansiedlung zu lokalisieren ${ }^{28}$. Dagegen spricht allerdings die bei Herodot 1, 26 erzählte Geschichte vom sieben Stadien langen Seil, mit dem der letzte Tyrann der Stadt, Pindaros, die Mauer mit dem Heiligtum der Artemis Ephesia verbunden haben soll. Da die maximal mögliche Entfernung zwischen dem Heiligtum und der Siedlung auf dem Ayasuluk aber nur zwei bis drei Stadien beträgt (vgl. Abb. 2), ist diese Identifikation abzulehnen, wenn man Herodot als verlässliche Quelle gelten lassen will. Andererseits ist klar, dass der Ayasuluk die strategisch beherrschende Stelle in der ephesischen Bucht einnahm und daher auch jede Nachfolgestadt von Apaša den Punkt zumindest militärisch besetzt halten musste.

So ist auch die von Pausanias erzählte Variante von der Gründung des ionischen Ephesos nach der Ankunft des Androklos und seiner Gefährten zu verstehen ${ }^{29}$. Während die um das Artemisheiligtum Wohnenden nichts zu befürchten brauchten und Eide mit den Ioniern tauschten, wurden die Leleger und

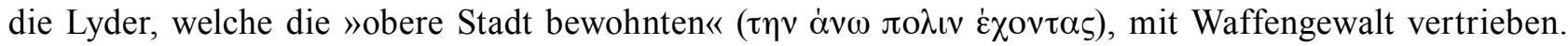
Während Pausanias aber nichts über den genauen Ort der Ansiedlung sagt, erzählen Athenaios und Strabon nach Kreophylos, dass Androklos nach der Vertreibung der Karer (statt der Lyder wie bei Pausanias) und Leleger seine Leute an der Tracheia bei der Quelle Hypelaios und dem benachbarten Koressos beim (späteren) Athenaion ansiedelte ${ }^{30}$.

Der Koressos(-Hafen) wird von den meisten Forschern nach eben diesen Angaben und nach Pausanias ${ }^{31}$ sowie weiteren römerzeitlichen Inschriften und literarischen Stellen, die einen Hafen und später einen Stadtteil Koressos und ein Koressisches Tor in der hellenistischen Stadtmauer erwähnen, heute auf der dem Ayasuluk und dem Artemision gegenüberliegenden Seite der Bucht (nahe dem römischen Stadion, vgl. Abb. 11 Nr. 79) lokalisiert; seine Entfernung zum Heiligtum beträgt in der Luftlinie tatsächlich sieben Stadien ${ }^{32}$ (Abb. 1. 2. 8). In diesem westlichen Küstenareal wurden zwar über ein weites Gebiet Keramikfunde ab dem mittleren 8. Jahrhundert v. Chr. und Teile einer vielleicht archaischen Stadtmauer festgestellt ${ }^{33}$, eine in die Zeit der

4-7 juin 1988 (Paris 1991) 128-130; A. Bammer, Les sanctuaires des VIII' et de VII ${ }^{\mathrm{e}}$ siècles à l'Artémision d'Ephèse, RA 1991, 63-83; A. Bammer, Fouilles à l'Artémision d'Ephèse (périodes géometrique et archaique): nouvelles données, RA 1993, 187-199; A. Bammer, Die Geschichte des Sekos im Artemision von Ephesos, ÖJh 62, 1993, Beibl. 137-161; Bammer - Muss, Artemision 33-38. A. Bammer, Zu den Schichten und Bauabfolgen im Artemision von Ephesos, in: T. Korkut (Hrsg.), 60. Anadolu'da Doğdu. Yaşında Fahri Işı1k’a Armağan. Festschrift Fahri Işı1k (Istanbul 2004) 69-88; A. Bammer, Der Peripteros im Artemision von Ephesos, Anatolia Antiqua - Eski Anadolu 13, 2005, 177-221.

${ }^{27}$ Vgl. Weiß1, Grundzüge 321-327.

${ }^{28}$ Büyükkolanc1, Excavations 41. 43.

${ }^{29}$ Paus. 7, 2, 6.

${ }^{30}$ Athen. 8, 62 p. 361; Strab. 14, 1, 4. 21.

${ }^{31}$ Paus. 5, 24, 7.

${ }^{32}$ Die lange Diskussion um den Koressos und die antiken Quellen am einfachsten nachzulesen bei Engelmann, Topographie 286-292; H. Engelmann, Der Koressos, ein ephesisches Stadtviertel, ZPE 115, 1997, 131-135; vgl. zur Kritik an einigen Punkten: Knibbe, Topographica Ephesiaca 213-219.

${ }^{33}$ Zur Fundevidenz zusammenfassend Scherrer, Topography 60 f.; vgl. jetzt auch M. Steskal, Die Geschichte der archäologischen Erforschung des Vediusgymnasiums und seines Umfeldes, in: M. Steskal - M. La Torre, Das Vediusgymnasium in Ephesos, ÖJh 70, 2001, bes. 221-225 und 231-234. 


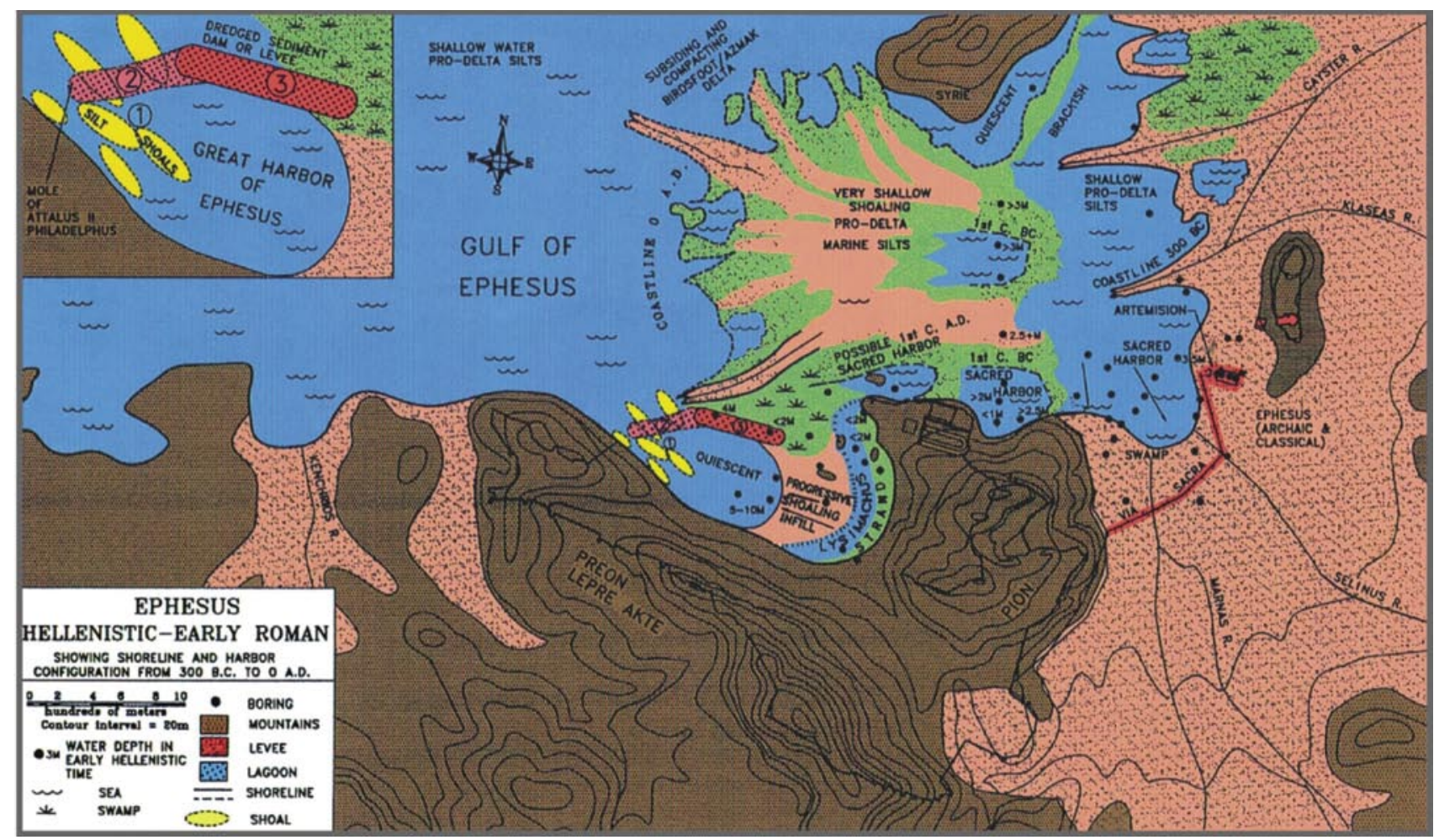

4 Küstenverlauf und Deltabildung in der ephesischen Bucht ungefähr im 1. Jh. v. Chr.

angeblichen Einwanderung ${ }^{34}$ um die Wende vom 2. zum 1. Jahrtausend v. Chr. zurückreichende archäologische Evidenz zu finden, gelang allerdings bisher nicht einmal annähernd ${ }^{35}$. Insofern muss bei der Zuweisung der ionischen Siedlung an diesen Küstenstreifen weiterhin gewisse Vorsicht walten.

Gewisse Indizien weisen darauf hin, dass die Siedlung am Küstenstreifen über dem Koressos-Hafen und auf der nach Westen vorspringenden Halbinsel (Abb. 2. 10), wohl die in den literarischen Angaben mehrfach genannte Tracheia ${ }^{36}$, im 6. Jahrhundert v. Chr. nicht oder zumindest nicht gänzlich aufgegeben worden war. So wurde bei neuesten Grabungen beim Stadion und im Hof des Vediusgymnasiums (Abb. 11 Nr. 81) neben älterem Material auch attisch-schwarzgefirnisste Keramik klassischer Zeit gefunden ${ }^{37}$, und auch auf dem sog. Akropolishügel (Abb. 11 Nr. 76) unmittelbar westlich des römischen Stadions kamen bei Versuchsgrabungen von J. Keil und St. Karwiese neben einer Peploskore des `Strengen Stils` aus Terrakotta Keramikfragmente des 5. und 4. Jahrhunderts v. Chr. zutage ${ }^{38}$.

Viel deutlicher aber manifestiert sich am Osthang des Panayırdağ direkt über dem Koressos-Hafen und unterhalb der wahrscheinlich zur archaischen Siedlung gehörenden Wehrmauer ab dem 5. Jahrhundert ein heiliger Bezirk, in dem mehrere Inschriften für Zeus Patroos und Apollon Patroos in den Felsen eingemeißelt worden waren ${ }^{39}$. Später, etwa im beginnenden Hellenismus, trat auch Meter Oreia Phrygie zu den verehrten Göttern, deren Kult dann bis in römische Zeit fortgesetzt wurde, wie zahlreiche Inschriften und

\footnotetext{
${ }^{34}$ Vgl. Kerschner, Wanderung 371-373.

${ }^{35}$ Angeblich wurde allerdings gerade in diesem Gebiet, beim Gymnasium des Vedius, eine primitive Figur entdeckt. Dargestellt ist ein Mann, der mit einem auf einem Dreifuß stehenden Gefäß hantiert. Nach Meinung von G. Hanfmann handelt es sich dabei um eine aus dem 13. Jh. v. Chr. stammende späthethitische Priesterfigur oder ein auf anatolische Vorstellungen und Kunstauffassung zurückgehendes Werk der `Dunklen Jahrhunderteく. Vgl. G. M. A. Hanfmann, A `Hittiteく Priest from Ephesus, AJA 66, 1962, 1-4 Taf. 1-4.

${ }^{36}$ Zur Benennung vgl. Scherrer, Siedlungsgeschichte $382 \mathrm{f}$.

${ }^{37}$ Unpubl.; freundlicher Hinweis M. Steskal und P. Turnovsky (Wien).

38 J. Keil, XII. Vorläufiger Bericht über die Ausgrabungen in Ephesos, ÖJh 23, 1926, Beibl., bes. 252-256; H. Vetters, Ephesos. Vorläufiger Grabungsbericht 1979, AnzWien 117, 1980, 253 und Taf. 2.

${ }^{39}$ IvE 102 und 104. Vgl. dazu und zu einer unpublizierten Inschrift für Zeus Mainalos Scherrrer - Trinkl, Agora 264.
} 
Weihereliefs beweisen ${ }^{40}$. Ebenfalls am ehesten in das frühe 3. Jahrhundert v. Chr. gehört der auf der äußersten Spitze der Tracheia gegründete sog. Felsspalttempel (Abb. 9. 10. 11 Nr. 78). Die hier verehrte Gottheit ist unbekannt, zahlreiche hellenistische Terrakottafiguren deuten auf eine weibliche Kultinhaberin ${ }^{41}$.

Kehren wir noch einmal zum Ayasuluk zurück. In seiner isolierten Lage (Abb. 5. 6) liegt insofern auch ein entscheidender Nachteil, als im Kriegs- und Belagerungsfall den Verteidigern nur das in Zisternen gesammelte Wasser aus den winterlichen Regenfällen zur Verfügung stand. Zudem stand einer ausgedehnten städtischen Ansiedlung die Form der Bergkuppe entgegen, die an drei Seiten zwar von Steilhängen geschützt war, dafür aber ein $500 \mathrm{~m}$ langes und nur maximal $130 \mathrm{~m}$ breites Gipfelplateau bildete, das in byzantinischer Zeit auch folgerichtig zur Gänze ummauert wurde. Der - als einziger relativ sanfte - Südhang, hinab zum Artemision, wurde in die Siedlungsstrukturen nie eingebunden, wie die vor dem byzantinischen Haupttor (sog. Tor der Verfolgung) lokalisierten Gräber mykenischer und klassischer Zeit zeigen (Abb. 2). Beim Ausbau einer Stadt auf dem Gipfelplateau hätte also eine vergleichsweise lange Befestigungsmauer $(2,2 \mathrm{~km})$, die auch verteidigt hätte werden müssen, eine relativ kleine Fläche von nur $50000 \mathrm{~m}^{2}$ umgeben. Daher sind einer unreflektierten Gleichsetzung des Ayasuluk sowohl mit dem luwischen Apaša als auch mit dem ionischen Ephesos (>Androklos-Siedlung`) Bedenken entgegenzusetzen, und die Frage ist zu stellen, ob hier nicht doch nur eine Festung bestanden haben könnte, die großen Siedlungen der Epochen vor Kroisos aber an anderer Stelle zu suchen wären. In diesem Fall wäre das Heiligtum der Artemis Ephesia wohl am wichtigsten Hafenplatz der ephesischen Bucht im späten 2. und frühen 1. Jahrtausend angelegt worden, die Göttin müsste aber sodann keineswegs in der Nachfolge einer luwischen Stadtgottheit zu sehen sein. Vielmehr wäre der Kultplatz ursprünglich als Ort des Austausches außerhalb der von verschiedenen Ethnien bewohnten Siedlungen zu verstehen; erst unter Kroisos trat in der Folge eine radikale Umstrukturierung zugunsten der Artemis Ephesia ein. Dass unter diesem Namen tatsächlich sehr verschiedenartige Vorstellungen subsumiert worden sein dürften, zeigt der Wandel des Kultbildes bzw. der Propaganda mit verschiedenen Bildformen auf den lokalen Münzen, wobei die `typische` Erscheinungsform der >vielbrüstigen` Gottheit erst in der späten Attalidenzeit einsetzt und sich nach der Übernahme von Asia durch die Römer durchsetzt ${ }^{42}$.

Die von Kroisos geförderte archaisch-klassische Stadt beim Artemision (Abb. 2) ist völlig unerforscht. Einerseits liegt sie bis zu $6 \mathrm{~m}$ unter dem Alluvium der von Süden kommenden Flüsse begraben, andererseits verbieten der hier liegende Westrand des Ortes Selçuk und vor allem der zugehörige islamische Friedhof unmittelbar südlich der am Artemision vorbeiführenden Fernstraße zusammenhängende, großflächige Untersuchungen. Am Südrand dieser Straße, ungefähr 300 bzw. 450 m westsüdwestlich des Artemisions, unternahm bereits J. Keil im Jahr 1929 kleine Tiefgrabungen, im Zuge derer im beginnenden Grundwasserbereich bei etwa 2,5 m über dem (heutigen) Meeresspiegel Schichten und Keramik klassischer Zeit erfasst werden konnten ${ }^{43}$. Weitere Keramikfragmente klassischer Zeit wurden 1983 in den ältesten Schichten einer von St. Karwiese durchgeführten (unpublizierten) Untersuchung anlässlich des Umbaus der alten Karawanserei in einen zum Efes Müzesi Selçuk gehörenden Konferans Salonu am westlichen Ortsrand von Selçuk, am Beginn der Hauptstraße nach Kuşadası und etwa 500 m östlich der von J. Keil untersuchten Stellen, geborgen ${ }^{44}$.

40 J. Keil, Denkmäler des Meterkultes, ÖJh 18, 1915, 66-78; Keil (Anm. 38) 256-261; F. Naumann, Die Ikonographie der Kybele in der phrygischen und der griechischen Kunst, IstMitt Beih. 28 (Tübingen 1983) bes. 214-216; M. J. Vermaseren, Corpus Cultus Cybele Attidisque (CCCA) I. Asia minor, EPRO 50/1 (Leiden 1987) 184-202; IvE 107-109. 1215-1224; F. Soykal, Denkmäler des Kybele-Meterkultes in Ephesos (Diss. Wien 1998); E. Heinzel, Der Kybelekult und die Dreigötterreliefs aus Ephesos, in: Scherrer u. a., Steine 35-42; M. Büyükkolanc1, Ein Vierfigurenrelief des Meterkultes vom Panayırdağ in Ephesos, in: Scherrer u. a., Steine 19-21; E. Vikela, Bemerkungen zu Ikonographie und Bildtypologie des Meter-Kybelereliefs: Vom phrygischen Vorbild zur griechischen Eigenständigkeit, AM 116, 2001, bes. 108-111 Taf. 20, 3.

${ }^{41}$ Grabungsbericht und Rekonstruktion des Tempels als Prostylos: Karwiese, Koressos 215. 219; Karwiese, Artemis 54.177 zu Abb. 15. Datierung in das 3. Jh. v. Chr.: RE Suppl. XII (1970) 1646 s. v. Ephesos B: Archäologischer Teil (W. Alzinger); J. Keil, XIII. Vorläufiger Bericht über die Ausgrabungen in Ephesos, ÖJh 24, 1929, Beibl. 48-50; V. Gassner, Kultkeramik aus dem sgn. Felsspalttempel in Ephesos, in: SERES 2007, IV (Ankara 2007) 386-398; vgl. zu den Terrakottafunden auch: H. Vetters, Ephesos. Vorläufiger Grabungsbericht 1977, AnzWien 115, 1978, 271 f. Taf. 9 f.; H. Vetters, Ephesos. Vorläufiger Grabungsbericht 1978, AnzWien 116, 1979, 130 Abb. 13 Taf. 12 f.

${ }^{42}$ Zusammenfassend Brenk, Artemis, bes. $159 \mathrm{f}$.

${ }^{43}$ J. Keil, XV. Vorläufiger Bericht über die Ausgrabungen in Ephesos, ÖJh 26, 1930, Beibl. 34-38.

${ }^{44} \mathrm{Zu}$ dieser Grabung vorläufig H. Vetters, Ephesos. Vorläufiger Grabungsbericht 1983, AnzWien 121, $1984,211$. 


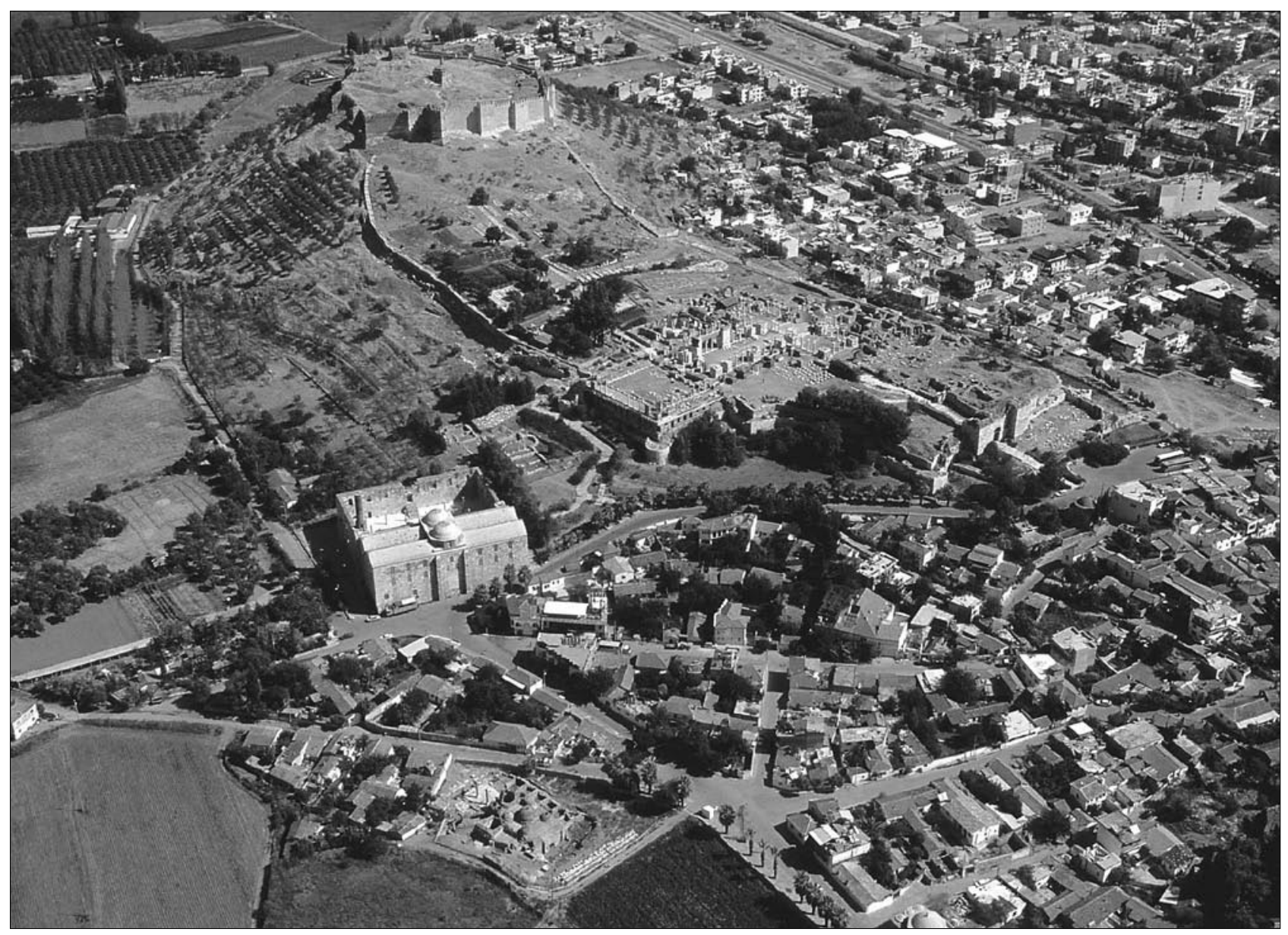

5 Der Ayasuluk, Luftbild von Südsüdwest: auf der Spitze die türkische Festung, davor die byzantinische Ummauerung von Hagios Theologos mit der Johanneskirche; am Westhang Ruinen eines byzantinischen Klosters, daneben die Isa Bey Moschee

Neben unstratifizierten Streufunden archaisch-klassischer Keramik an der Südostflanke des Panayırdağ im Bereich östlich des Magnesischen Tores ${ }^{45}$ (Abb. 11 Nr. 18), also außerhalb der hellenistisch-römischen Stadt, am Osthang des Bülbüldağ oberhalb des sog. Staatsmarktes (Abb. 11 Nr. 28$)^{46}$ und auf der wasserlosen ehemaligen Insel Syrie ${ }^{47}$ (Abb. 1. 2), dem heutigen Kurudağ, nordwestlich des Artemisions, ist nur eine weitere Siedlungsstelle der archaisch-klassischen Zeit genau lokalisierbar: Am Westrand der hellenistisch-römischen Tetragonos Agora (Abb. 11 Nr. 51; Abb. 12) wurden unter der römischen Weststoa bzw. dem anschließenden Platzniveau in durchschnittlich $5 \mathrm{~m}$ Tiefe (bei $0,90 \mathrm{~m}$ unter bis $0,60 \mathrm{~m}$ über heutigem Meeresspiegel) mehrere Wohnhäuser aufgedeckt ${ }^{48}$. Die Zeitstellung reicht vom letzten Drittel des 8. Jahrhunderts v. Chr. bis um die Mitte des 6. Jahrhunderts v. Chr. Eine älteste Holzbauphase wird rasch von teilweise ovalen, teilweise rechteckigen Einraumbauten mit Steinsockelmauern und Lehmwänden abgelöst. Nach einer Zerstörung durch Brand um oder bald nach $670 \mathrm{v}$. Chr. folgen drei weitere Bauperioden mit immer komplexeren Grundrissen, wobei in der letzten Bauperiode im frühen bis mittleren 6. Jahrhundert v. Chr. zwei, anscheinend von einer schmalen Gasse getrennte Häuser mit ca. 16 m Länge im Grabungsareal vorhanden waren. Von Haus HA-Ost wurden drei parallele Raumfluchten mit 11 verschiedenen Räumen in einer Breite von ungefähr $12 \mathrm{~m}$ freigelegt; insgesamt dürfte der Grundriss etwa quadratisch gewesen sein.

45 J. Keil, XIV. Vorläufiger Bericht über die Ausgrabungen in Ephesos, ÖJh 25, 1929, Beibl. 36 f.

${ }^{46}$ Unpubl., Survey des Verfassers 1997; keramische Funde, dabei der Fuß einer Amphore des 5. Jhs. v. Chr., im Depot des österreichischen Grabungshauses in Selçuk.

${ }^{47}$ Unpubl., Survey des Verfassers 1997; Funde archaischer Keramik im Depot des österreichischen Grabungshauses in Selçuk.

${ }^{48}$ Für einen zusammenfassenden Bericht s. P. Scherrer in: Scherrer - Trink1, Agora 59-64. 
Wahrscheinlich gruppierten sich die Räume an drei Seiten um einen großen, offenen Hof im Norden des Hauses. In das zerstörte Haus wurde im 6. Jahrhundert v. Chr. ein Töpferofen eingetieft.

Etwas weiter südlich wurde nach der Mitte des 5. Jahrhunderts v. Chr., also mindestens 100 Jahre nach Aufgabe der Häuser, auf bereits deutlich höherem Niveau ( $0,90 \mathrm{~m}$ über Meeresspiegel) eine gewerbliche Anlage mit vier in den Boden eingelassenen Becken mit Lehmziegelböden und Steinwänden und einem mit Steinen ausgekleideten Brunnen angelegt ${ }^{49}$. Die Anlage stand anscheinend mindestens bis in die Zeit um 350 v. Chr. in Verwendung und wurde spätestens bei der Errichtung der hellenistischen Neustadt bzw. der Agora in der ersten Hälfte des 3. Jahrhunderts v. Chr. durch Geländeplanierungen außer Funktion gesetzt.

Aufgrund der topographischen Angaben bei Strabon 14, 1, 4 darf die Benennung dieser Siedlung mit dem mehrfach überlieferten Dorf Smyrna ${ }^{50}$ als gesichert oder zumindest als sehr wahrscheinlich gelten (Abb. 2). Die älteste im Befund feststellbare Zerstörung zwischen 670 und 660 v. Chr. könnte dann die vom Dichter Kallinos ${ }^{51}$ angesprochene Zerstörung durch die Kimmerier sein. Das Dorf lag jedenfalls in einer kleinen Bucht am damaligen Meeresstrand (Abb. 10), direkt an einer Straßengabelung: Von der von Ephesos nach Pygela und zur Mykale führenden Straße zweigte an der Stelle des römischen Agora-Südtores, das deshalb Triodos ${ }^{52}$ genannt wurde, ein Weg ab, der am westlichen Fuß des Panayırdağ der Küste entlang nach Koressos führte.

Die wenigen bisher vorgenommenen Stichproben in den Gräberfeldern der archaisch-klassischen Zeit (Abb. 1. 2) sind trotz des geringen Materialumfangs durchaus geeignet, das Siedlungsbild dieser Zeit zu ergänzen.

Am Fuß der landeinwärts gerichteten Ostseite des Ayasuluk wurde bei Bauvorhaben ein kleiner Teil des Gräberfeldes angeschnitten, das sich entlang der antiken Überlandstraße von Ephesos nach Smyrna (Abb. 6) ausbreitete. In der nur etwa $70 \mathrm{~m}^{2}$ großen Baugrube im Zwickel zwischen der alten und der neuen Hauptstraße von Selçuk nach Izmir wurden insgesamt acht Grablegen des 8.-4. Jahrhunderts v. Chr. von Archäologen des Efes Müzesi Selçuk dokumentiert. Nach dem vorläufigen Grabungsbericht ${ }^{53}$ ist Grab 7 ein Brandgrab der spätgeometrischen Zeit (8. Jh. v. Chr.), die Steinkistengräber 1-5 gehören dem späten 5. Jahrhundert v. Chr. an; weitere, nicht in Gräbern gefundene Keramik deutet jedoch eine kontinuierliche Belegung bis in die frühhellenistische Zeit an. Noch unpublizierte Körpergräber klassischer Zeit wurden im Zuge eines Hausbaus beim Parkplatz vor dem byzantinischen \Tor der Verfolgungく, also in unmittelbarer Nähe der erwähnten Bestattungen spätmykenischer Zeit, aufgefunden (Abb. 2). Der Gräberfeldbereich umfasste somit anscheinend den gesamten Ost- und Südhang des Ayasuluk, nach Westen zu schloss, den wenigen Befunden nach zu urteilen, die archaisch-klassische Siedlung unmittelbar an.

Weitere Gräber des 6. und 5. Jahrhunderts v. Chr. wurden im Tal Abu-Hayat gefunden ${ }^{54}$, ein Grablöwe (4. Jh. v. Chr.?) beim Tavşantepe ${ }^{55}$ (Abb. 1). Diese Fundstellen liegen nahe der Trasse der antiken Fernstraße von Smyrna über Ephesos nach Magnesia am Mäander. Der Löwe vom etwa $500 \mathrm{~m}$ südlich der archaischklassischen Stadt gelegenen Tavşantepe könnte ein bedeutendes Einzelgrab auf dem an dieser Fernstraße gelegenen Hügel bewacht haben. Die Gräber im Abu Hayat deuten eher auf die Existenz einer dörflichen Siedlung in diesem ungefähr $2 \mathrm{~km}$ von der Stadt entfernten Tal hin.

Kleine Teile eines geschlossenen, großen Gräberfeldes (Abb. 2) entlang der Überlandstraße von Ephesos nach Pygela wurden im Einschnitt zwischen Bülbüldağ und Panayırdağ, also unter dem sog. Staatsmarkt, entlang der sog. Kuretenstraße und im Bereich der >Hanghäuser〈 ausgegraben. Das Gräberfeld setzt sich beiderseits des Agora-Südtores fort und reicht anscheinend bis mindestens zum Agora-Nordtor weiter, beglei-

\footnotetext{
${ }^{49} \mathrm{Zu}$ den Befunden und dem umfangreichen Fundmaterial klassischer Zeit vgl. die abschließende Publikation von P. Scherrer - E. Trink1 - M. Lawall u. a. in: Scherrer - Trink1, Agora 69-148.

${ }^{50}$ H. Engelmann, Beiträge zur ephesischen Topographie, ZPE 89, 1991, 275-282; P. Scherrer in: Scherrer - Trink1, Agora, bes. $60 \mathrm{f}$.

${ }^{51}$ Überliefert bei Strab. 14, 1, 4; vgl. B. Gentili - C. Prato, Poetae elegiaci. Testimonia et fragmenta I (Leipzig 1979) 6 Nr. $2-4$.

52 D. Knibbe - H. Engelmann - B. İplikçioğlu, Neue Inschriften aus Ephesos XII, ÖJh 62, 1993, 123 f. Nr. 13.

${ }^{53}$ C. İçten - A. Evren, Selçuk-Efes 3447 Parsel Kurtarma Kazısı, in: 8. Müze Kurtarma Kazıları Semineri (Ankara 1997) $85-110$.

${ }^{54}$ Ö. Özyiğit, Spätarchaische Funde im Museum von Ephesos und die Lage von Alt-Ephesos, IstMitt 38, 1988, 83-96 bes. 84 f.

${ }^{55}$ S. Erdemgil - A. Evren, Efes Tavşantepe Aslan1, TAD 30, 1992, 71-82.
} 


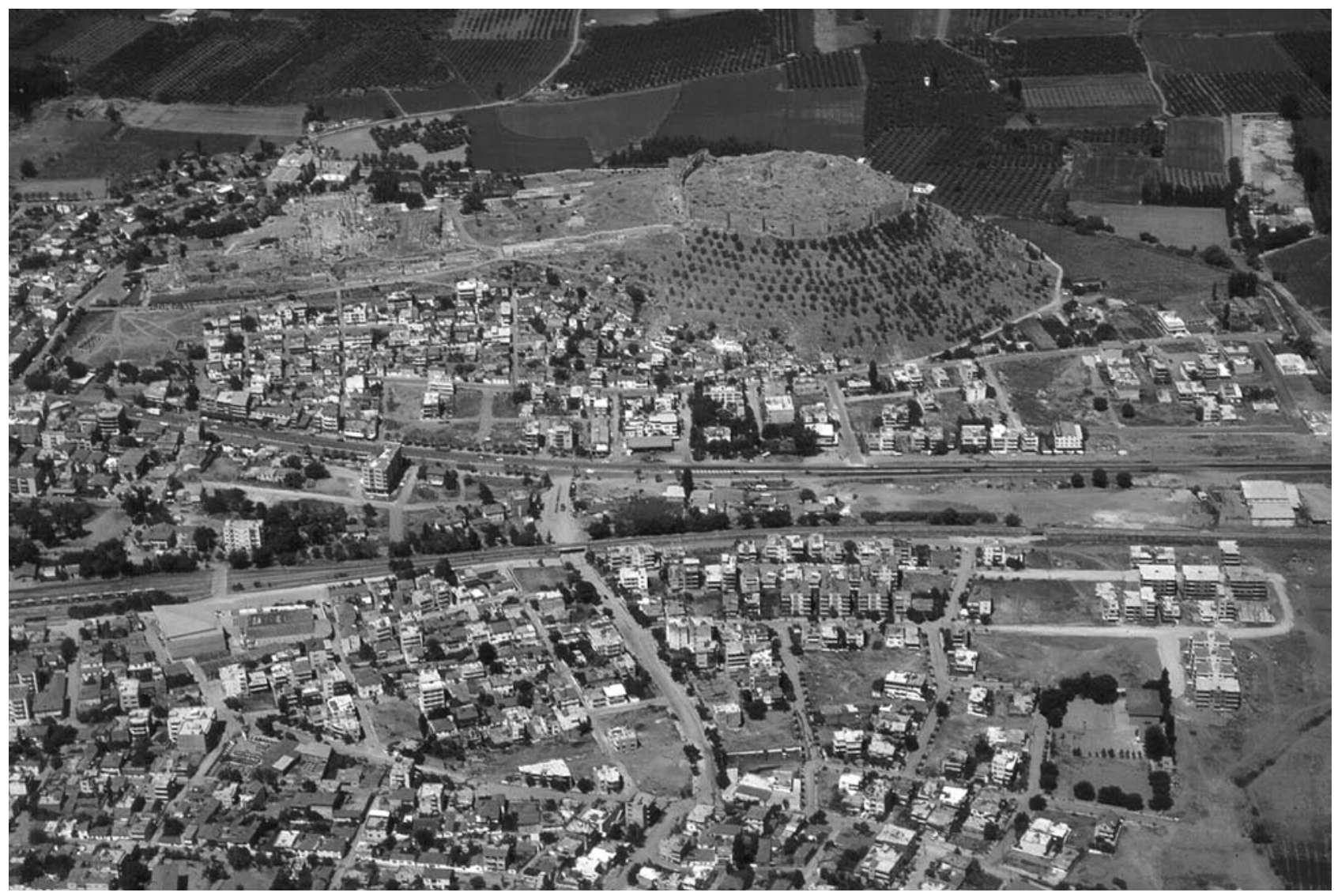

6 Der Ayasuluk, Luftbild von Osten: auf der Spitze die türkische Festung, davor die byzantinische Ummauerung von Hagios Theologos mit der Johanneskirche; direkt vor dem Osthang verläuft die alte Straße nach Izmir, davor die moderne Fernstraße

tet die Straße somit auf einer Länge von wenigstens 700 m. Die bekannten Körperbestattungen gehören dem späten 6. bis ausgehenden 4. Jahrhundert v. Chr. an. Teilweise wurden kleine Tumuli nachgewiesen, neben Erdgräbern oder Bestattungen unter zusammengestellten Dachziegeln überwiegen Stein- und Tonsarkophage $^{56}$. Interessanterweise sind die bekannten Gräber entlang dieser Straße alle erst nach dem Zeitpunkt zu datieren, an dem die Siedlungen durch den Synoikismos des Kroisos eigentlich aufgegeben worden sein sollten. Tatsächlich aber muss vermutet werden, dass die älteren Gräber, vor allem die Brandgräber des 8./7. Jahrhunderts v. Chr., in den kleinräumigen Untersuchungen nicht dokumentiert werden konnten und infolge der starken Störung der meisten Befunde durch jüngere Körpergräber und hellenistische sowie römische Bauten meist nicht erhalten geblieben sind.

Zusammenfassend lässt sich eine nur scheinbar überraschende Feststellung zur Besiedlungsstruktur von Ephesos in spätarchaischer und klassischer Zeit treffen: Die kontinuierliche Benützung der Gräberfelder an den Fernstraßen in einer Entfernung bis zu mehreren Kilometern von der Stadt beim Artemision bis in spätklassische oder frühhellenistische Zeit, die Weiterbenützung des Koressos-Hafens im 5. Jahrhundert v. Chr. und über diesem die Anlage eines Heiligtums am Berghang für Zeus Patroos und Apollon Patroos im späteren 5. Jahrhundert v. Chr. sowie die Aufdeckung eines Gewerbebetriebes hochklassischer Zeit unter der hellenistischen Agora im Verbauungsgebiet des spätgeometrisch-archaischen Dorfes Smyrna (?) sind als deutliche Indizien dafür zu werten, dass der Synoikismos des Kroisos entweder nie in vollständiger Form verwirklicht worden war oder zumindest verschiedene Gruppen bald wieder in die früheren Wohngebiete zurückkehrten, wohl weil die Lage von Koressos und Smyrna bei natürlichen Meereshäfen für Fischer, Händler und andere Berufsgruppen Vorteile brachte. Gerade die betonte Zuwendung an die >väterlichen<

\footnotetext{
${ }^{56}$ Zusammenfassend mit Publikation von Neufunden 1998 jetzt P. Scherrer - E. Trink1 in: Scherrer - Trink1, Agora $149-164$.
} 
Götter Zeus und Apollon könnten auch auf >radikale Griechen ‘ deuten, die bald in ihre angestammte Polis zurückzogen und ihren Hafen Koressos den griechischen bzw. athenischen Interessen zur Verfügung stellten, auch oder gerade dann, wenn diese gegen die pro-persisch bzw. später pro-spartanisch orientierte Stadt beim Artemision gerichtet waren.

\section{Von Arsinoeia nach Hagios Theologos: Von der Neugründung des Lysimachos bis zur byzantinischen Zeit}

Im Zeitraum 301/300 v. Chr. bemächtigte sich der Diadochenfürst Lysimachos erstmals der Stadt Ephesos und besaß sie dann von 287 bis zu seinem Tode auf dem Schlachtfeld von Kuropedion im Jahr 281. Er zwang die Ephesier zum Bau einer neuen, nach seiner Gattin oder seiner Tochter Arsinoeia genannten Stadtanlage an den Abhängen des auch Lepre Akte genannten Preon ${ }^{57}$, des heutigen Bülbüldağ, und des Pion $^{58}$, des südlichen Teils des heute mit dem Namen Panayırdağ bezeichneten Doppelberges, mit einem Hafen, irgendwo in jener Bucht, in der bis dahin das Dorf Smyrna situiert war ${ }^{59}$ (Abb. 2. 14 Nr. III). Nach damals modernsten strategischen Überlegungen wurde über die beiden Bergkämme eine mit vielen Türmen und zumindest drei Stadttoren ausgestattete, von Strabon ausdrücklich dem König zugeschriebene Stadtmauer von etwa 8 oder $9 \mathrm{~km}$ Länge in Emplektontechnik errichtet ${ }^{60}$, die über weite Strecken bis heute gut erhalten oder zumindest anhand der für ihre Errichtung in den Fels geschlagenen Rinnen verfolgbar ist ${ }^{61}$. Problematisch sind nur der Verlauf des Mauerabschnittes von der Höhe des Panayırdağ herab zur damaligen Küste sowie die Frage, ob es eine Seemauer gegeben hat und wo diese verlaufen sein kann. Hier hat die 1998 erfolgte Auffindung eines Torbaus aus dem frühen 3. Jahrhundert v. Chr. unter dem römischen Nordtor der Tetragonos Agora (Abb. 11 Nr. 51) wichtige Anhaltspunkte erbracht: Wahrscheinlich handelt es sich bei dieser Anlage um das \Koressische Tor` der ursprünglichen hellenistischen Stadtplanung ${ }^{62}$. Dann könnten Teile der westlich von hier zum Hafen der römischen Kaiserzeit verlaufenden, spätantiken Stadtmauer auf einer hellenistischen Seemauer aufsitzen, die geoelektrischen Messungen zufolge ungefähr entlang der damaligen Küstenlinie parallel zum Bülbüldağ verlaufen sein muss. Das bereits von J. T. Wood entdeckte Haupttor der Stadt, in Inschriften und von Pausanias ${ }^{63}$ als Magnesisches Tor bezeichnet, lag an der Landseite im Osten. In seiner ursprünglichen Gestalt scheint sich das eigentliche Tor an der Innenseite eines großen, offenen Torhofs befunden zu haben, der vorn von flankierenden Türmen gedeckt wurde ${ }^{64}$.

Das große Theater (Abb. 9. 10. 11 Nr. 56) nördlich der Agora besitzt nach jüngsten Grabungsergebnissen ebenfalls einen auf das 3. Jahrhundert v. Chr. zurückgehenden $\mathrm{Kern}^{65}$; es bildete wohl den nördlichsten Punkt der ummauerten lysimachischen Gründung ${ }^{66}$. Der in kaiserzeitlichen Inschriften als Tetragonos Agora bezeichnete Marktplatz wurde vermutlich bereits unter Lysimachos angelegt und ab spätestens 260 v. Chr. mit Hallenanlagen ausgestattet. Diese wurden bis in das 1. Jahrhundert v. Chr. hinein mehrfach erweitert und monumentalisiert und bildeten in späthellenistischer Zeit einen mehr oder weniger geschlossen umlaufenden Baukörper rund um den Agorahof ${ }^{67}$.

\footnotetext{
57 Vgl. Strab, 14, 1, 4.

${ }_{58}$ Plin. nat. 5, 115 schreibt von Ephesos attolitur monte Pione.

${ }^{59}$ Zur richtigen Namenszuweisung der beiden Stadtberge mit allen Quellen vgl. Engelmann, Topographie 282-286.

${ }^{60}$ Strab. 14, 1, 21.

${ }^{61} \mathrm{Zu}$ dem gut erhaltenen Abschnitt auf dem Bülbüldağ aus festungsbautheoretischer Sicht und zu der Datierung der Mauer jetzt: Th. Marksteiner, Bemerkungen zum hellenistischen Stadtmauerring von Ephesos, in: Friesinger - Krinzinger, Forschungen 413-419; zum Verlauf der Mauern und einer abgetrennten Zitadelle auf dem Nordgipfel des Panayırdağ: Scherrer, Topography 62 f. Abb. 3-6.

${ }^{6}$ P. Scherrer in: Scherrer - Trinkl, Agora 13 f.; Scherrer, Stadttore 69-72.

${ }_{63}$ Paus. 7, 2, 6.

${ }^{64}$ Zum Tor jetzt: Scherrer, Stadttore 63-69 bes. 66 f. mit Abb. 6 (zur hellenistischen Bauform).

65 Jahresbericht 2002 des Österreichischen Archäologischen Instituts, ÖJh 72, 2003, 308 f.

${ }^{66}$ Scherrer, Stadttore 69.

${ }^{67} \mathrm{Zu}$ den Ergebnissen der Ausgrabungen im Agora-Westbereich jetzt P. Scherrer in: Scherrer - Trinkl, Agora 15-19.
} 


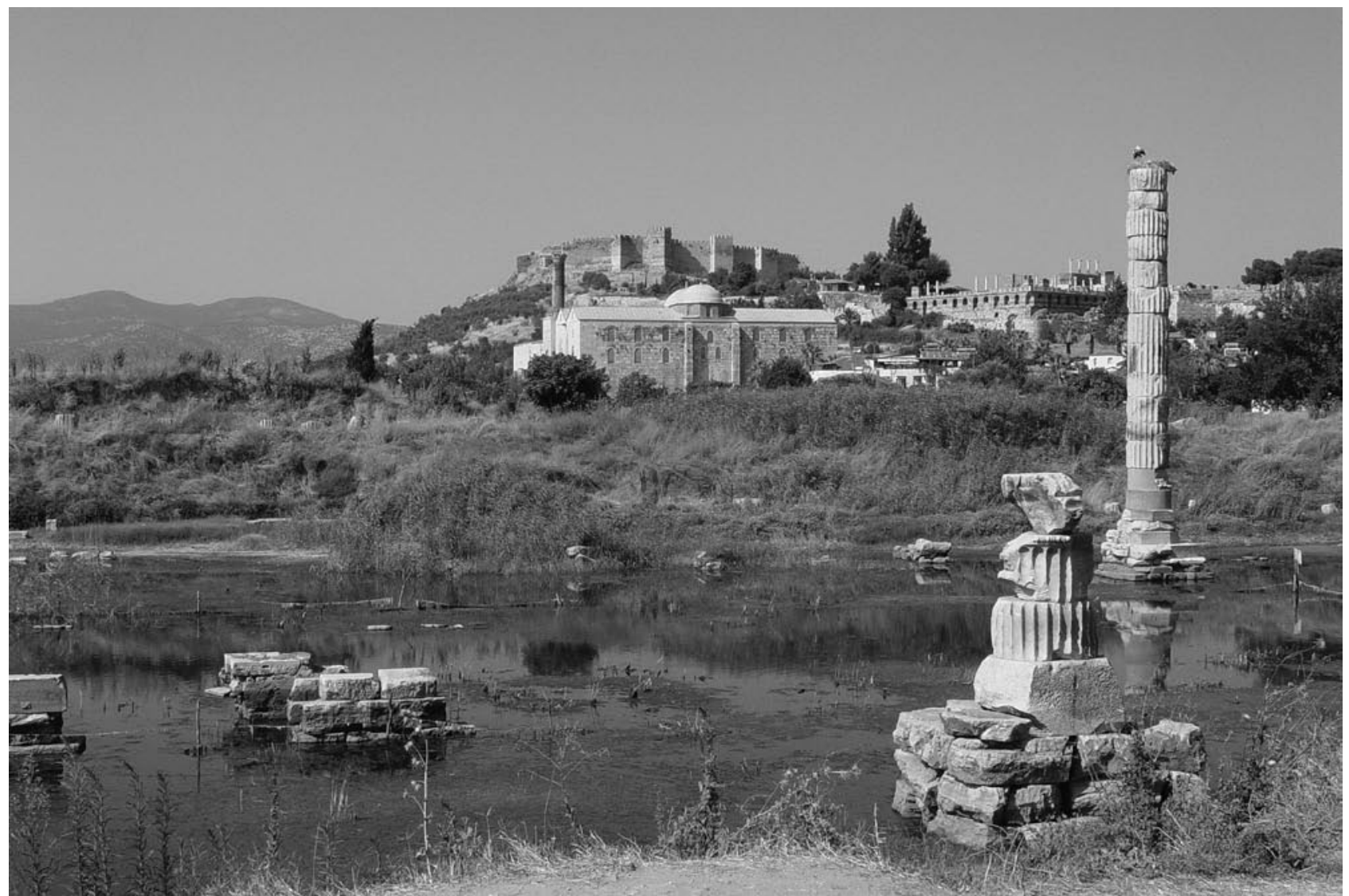

7 Das Artemision, Bereich des klassischen Tempels, überschwemmt vom Grundwasser, Blick von Südwesten; im Hintergrund der Ayasuluk mit türkischer Festung, Johanneskirche und Isa Bey Moschee

Im Sattel am oberen Ende des Einschnittes zwischen Bülbüldağ und Panayırda $\breve{g}$, über einem Teil des spätarchaisch-klassischen Gräberfeldes, lag mindestens seit dem 2. Jahrhundert v. Chr. ein Gymnasium ${ }^{68}$, das im Zuge der augusteischen Neuplanung der Stadt zur Keimzelle verschiedener Kaiserkultanlagen unter Einbindung des Prytaneions (Abb. 11 Nr. 28-32) werden sollte. Nahe dem unteren, westlichen Ende der schrägen, wohl Embolos genannten Wegverbindung zwischen diesem Gymnasium und der Agora wurde im späten 2. oder frühen 1. Jahrhundert ein großes Nymphäum (Abb. 11 Nr. 46) errichtet, dessen Giebelreliefs Szenen aus dem Stadtgründungsmythos rund um den Ktistes Androklos zeigen ${ }^{69}$.

Abgesehen von kleinen Ausschnitten späthellenistischer Wohn- und Gewerbebauten, etwa im Hof des sog. Serapeions ${ }^{70}$ (Abb. 11 Nr. 52; Abb. 12) westlich der Agora und unter den sog. Hanghäusern am Embo$\operatorname{los}^{71}$ (Abb. 11 Nr. 45), ist von der hellenistischen Stadt sonst nicht viel Konkretes bekannt. Der vermutliche Zentrumsbereich am unteren Hangteil des Bülbüldağ (vgl. Abb. 9) entlang der damaligen Küste ist noch völlig unerforscht.

$\mathrm{Ab}$ dem ausgehenden 1. Jahrhundert v. Chr. lässt sich, teilweise angeregt von Octavian-Augustus selbst, der schon 29 v. Chr. den Italikern in Ephesos den Bau eines Tempels für Divus Iulius und Dea Roma befahl ${ }^{72}$

${ }^{68}$ Engelmann, Kaiserkult 288 f.; C. P. Jones, Atticus in Ephesus, ZPE 124, 1999, 89-94; H. Thür, Das Gymnasium an der oberen Agora in Ephesos, in: E. Christof u. a. (Hrsg.), ПOTNIA $\Theta H P \Omega N$. Festschrift Gerda Schwarz (Wien 2007) $403-414$.

${ }^{69}$ H. Thür, Der ephesische Ktistes Androklos und (s)ein Heroon am Embolos, ÖJh 64, 1995, 63-103.

${ }^{70}$ P. Scherrer, Das sogenannte Serapeion in Ephesos: ein Mouseion?, in: A. Hoffmann (Hrsg.), Ägyptische Kulte und ihre Heiligtümer im Osten des Römischen Reiches, Byzas 1 (Istanbul 2005) 112 f. Abb. 2.

${ }^{71}$ S. Ladstätter - C. Lang-Auinger, Zur Datierung und kunsthistorischen Einordnung einer Apollon Kitharodos-Statuette, in: F. Krinzinger (Hrsg.), Studien zur hellenistischen Keramik in Ephesos, ErghÖJh 2 (Wien 2001) 71-81.

${ }^{72}$ Cass. Dio 51, 20, 6-7. 


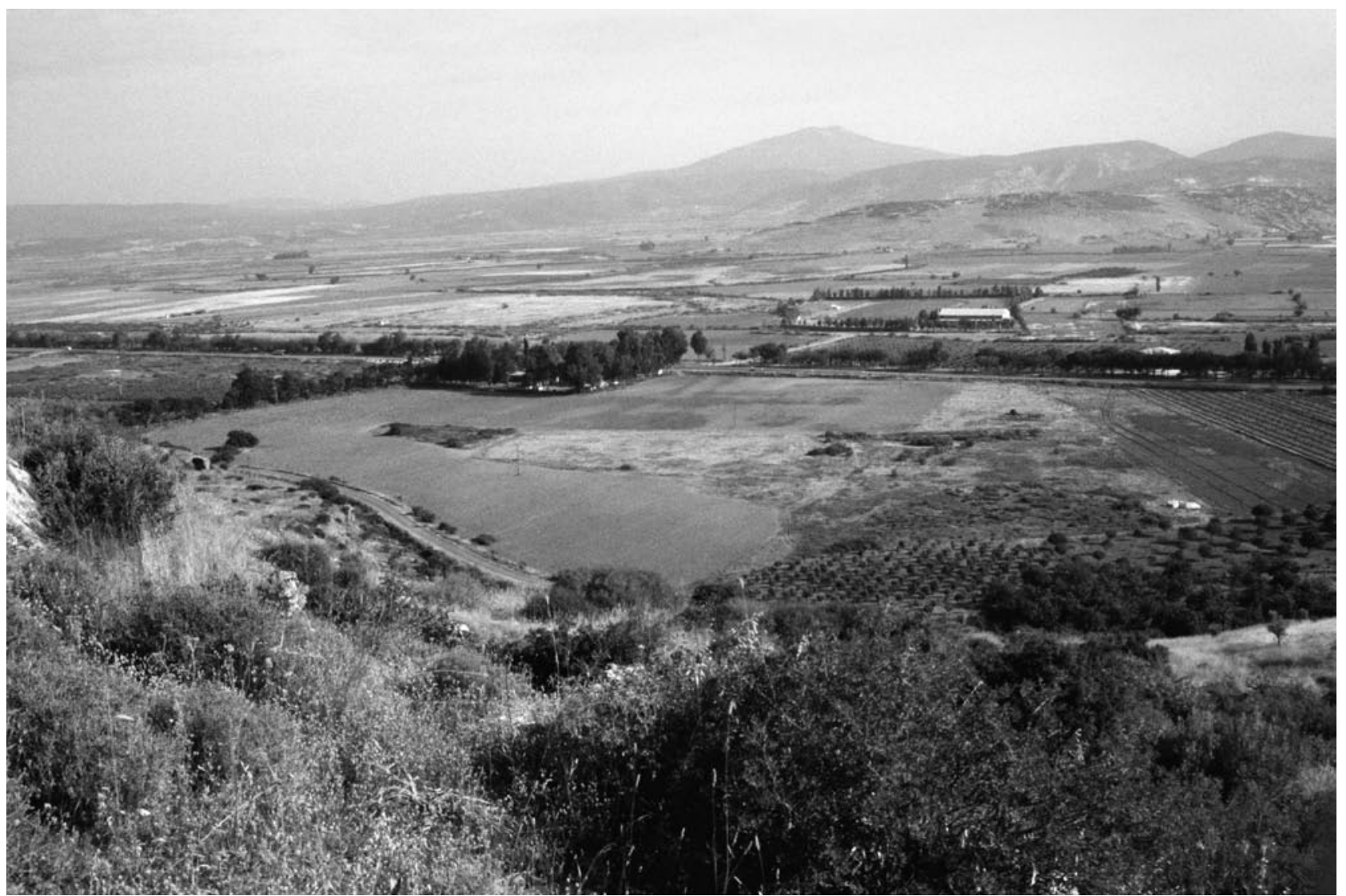

8 Blick vom Panayırdağ auf den ehemaligen Koressos-Hafen mit deutlich im Geländerelief sichtbarer Mole; darüber die Schwemmlandebene und - rechts oben - die ehemalige Insel Syrie; ganz oben das Gallesion-Gebirge am Nordrand der ephesischen Bucht

und zwei Wasserleitungen initiierte ${ }^{73}$, eine starke Bauaktivität des conventus civium Romanorum und seiner Mitglieder feststellen. Italische Kaufleute und kaiserliche Freigelassene errichteten in iulisch-claudischer Zeit die vergrößerte Tetragonos Agora über dem hellenistischen Marktplatz sowie den sog. Staatsmarkt mit zentralem prostylem Tempel, das Prytaneion, die Basilike Stoa und einen weiteren Kultplatz mit ionischem Peristyl im Bereich eines hellenistischen Gymnasiums ${ }^{74}$ (Abb. 11 Nr. 28-32). Gleichzeitig wurden diejenigen Teile der Stadt, die vornehmlich als öffentlicher Raum gewidmet waren, offensichtlich einem neuen Vermessungssystem mit einem Raster aus quadratischen Grundeinheiten zugeordnet ${ }^{75}$, der sich auch

73 Aqua Iulia: IvE 401; Aqua Throessitica: IvE 402. 3092.

${ }^{74}$ Grundlegende Gesamtschau und Besprechung der einzelnen Bauten: Alzinger, Architektur; zur Interpretation der Basilika zuletzt H. v. Hesberg, Die Basilika von Ephesos - Die kulturelle Kompetenz der neuen Stifter, in: Ch. Berns u. a. (Hrsg.), Patris und Imperium. Kulturelle und politische Identität in den Städten der römischen Provinzen Kleinasiens in der frühen Kaiserzeit. Kolloquium Köln, November 1998, BABesch Suppl. 8 (Leiden 2002) 149-158. Zu den Stiftern vgl. H. Halfmann, Städtebau und Bauherren im römischen Kleinasien. Ein Vergleich zwischen Pergamon und Ephesos, IstMitt Beih. 43 (Tübingen 2001) bes. 21-33; P. Scherrer, Der conventus civium Romanorum und kaiserliche Freigelassene als Bauherren in Ephesos in augusteischer Zeit, in: M. Meyer (Hrsg.), Neue Zeiten - Neue Sitten. Zu Rezeption und Integration römischen und italischen Kulturguts in Kleinasien, WForsch 12 (Wien 2007) 63-75. - Zur baulichen Entwicklung des Staatsmarktes vgl. jetzt H. Thür, Wie römisch ist der sog. Staatsmarkt in Ephesos, in: Meyer a. O. 77-90. Somit bereits überholt ist der noch immer auf einem Gegensatz-Kontinuum-Paar von hellenistischer Agora und römischem Forum aufbauende Versuch von U. Kenzler, Die augusteische Neugestaltung des Staatsmarktes in Ephesos, Hephaistos 24, 2006, 169-181.

${ }^{75}$ Zur theoretischen Rekonstruktion der Stadtvermessung vgl. Scherrer, Topography 80-86 Abb. 3-20. Vor allem aufgrund ausgedehnter geophysikalischer Messungen seit dem Jahr 2000, aber in nicht diskutiertem Widerspruch zu verschiedenen ergrabenen Straßenevidenzen wurde nun ein in vieler Hinsicht abweichendes theoretisches Bild des Straßenrasters vorgelegt: St. Groh, Neue Forschungen zur Stadtplanung in Ephesos, ÖJh 75, 2006, 47-116 bes. 52-80. 


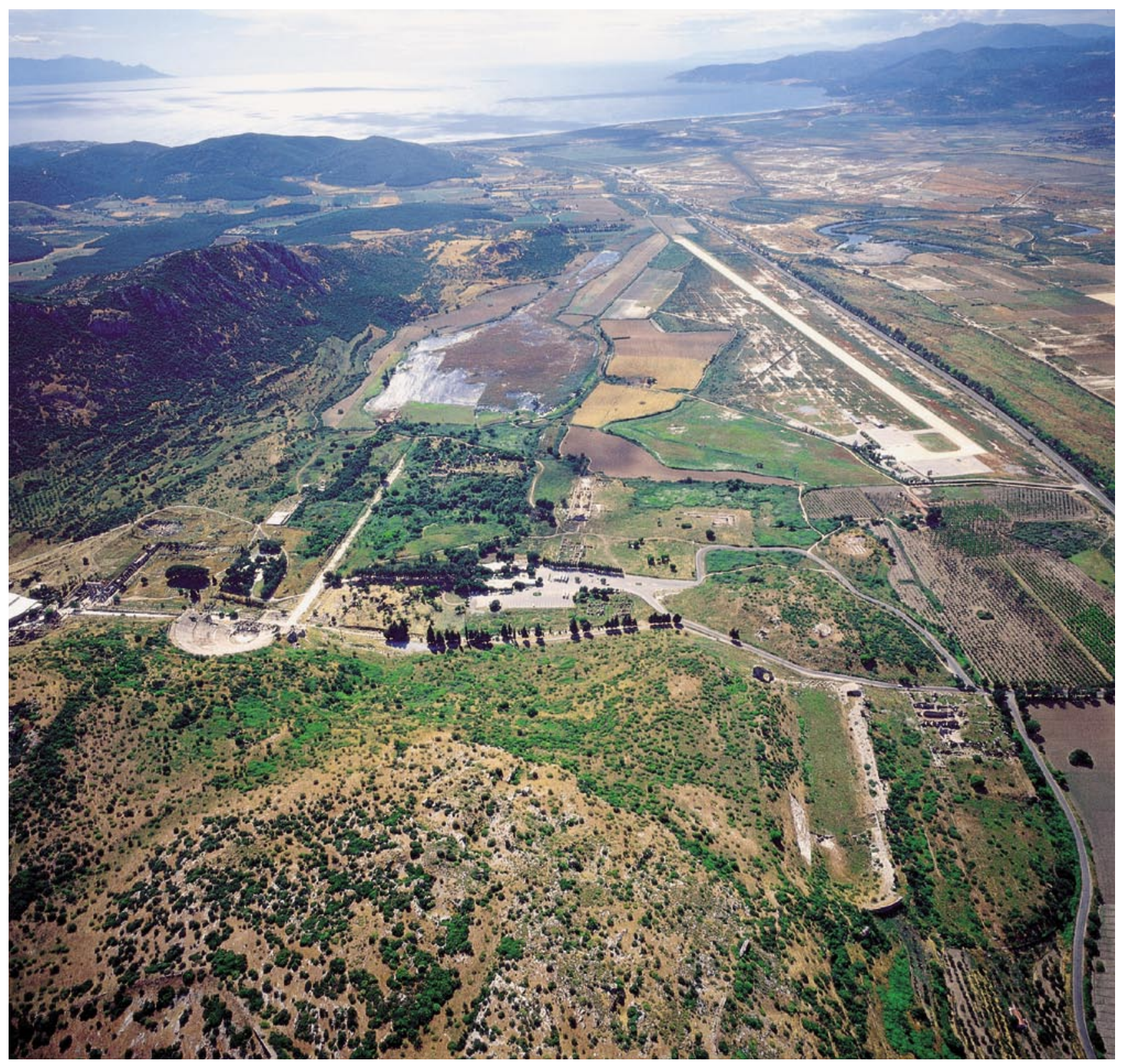

9 Luftbild von Osten über den Panayırdağ zum Meer über die hellenistisch-römische Stadt: links Tetragonos Agora, Theater und Arkadiane, dahinter das römische Hafenbecken; in der Bildmitte der moderne Parkplatz mit der anschließenden Ruine der Marienkirche (= Südstoa des Olympieion-Temenos); rechts das Stadion und das Koressos-Viertel an der Tracheia

über die Tetragonos Agora hinaus nach Norden in die ehemalige Meeresbucht erstreckte, die im Laufe des 1. Jahrhunderts und frühen 2. Jahrhunderts $\mathrm{n}$. Chr. völlig zugeschüttet und verbaut werden sollte. Hier wurde zuerst eine große Verbindungsstraße vom neuen domitianisch-traianischen Hafen zum Theater angelegt, die um 400 n. Chr. den Namen Arkadiane erhielt ${ }^{76}$ (Abb. 9. 10. 11 Nr. 57). Nördlich dieser Straße wurden unter Domitian die großen, den Spielen im Kaiserkult dienenden Sportstätten, das Sebaston Gymnasium und die Xystoi (Abb. 11 Nr. 65. 67), errichtet ${ }^{77}$, wohl unter Hadrian oder Antoninus Pius noch weiter westlich die

${ }^{76}$ P. Schneider, Bauphasen der Arkadiane, in: Friesinger - Krinzinger, Forschungen 467-478.

77 Architravinschrift IvE 427 (92/93 n. Chr.). 


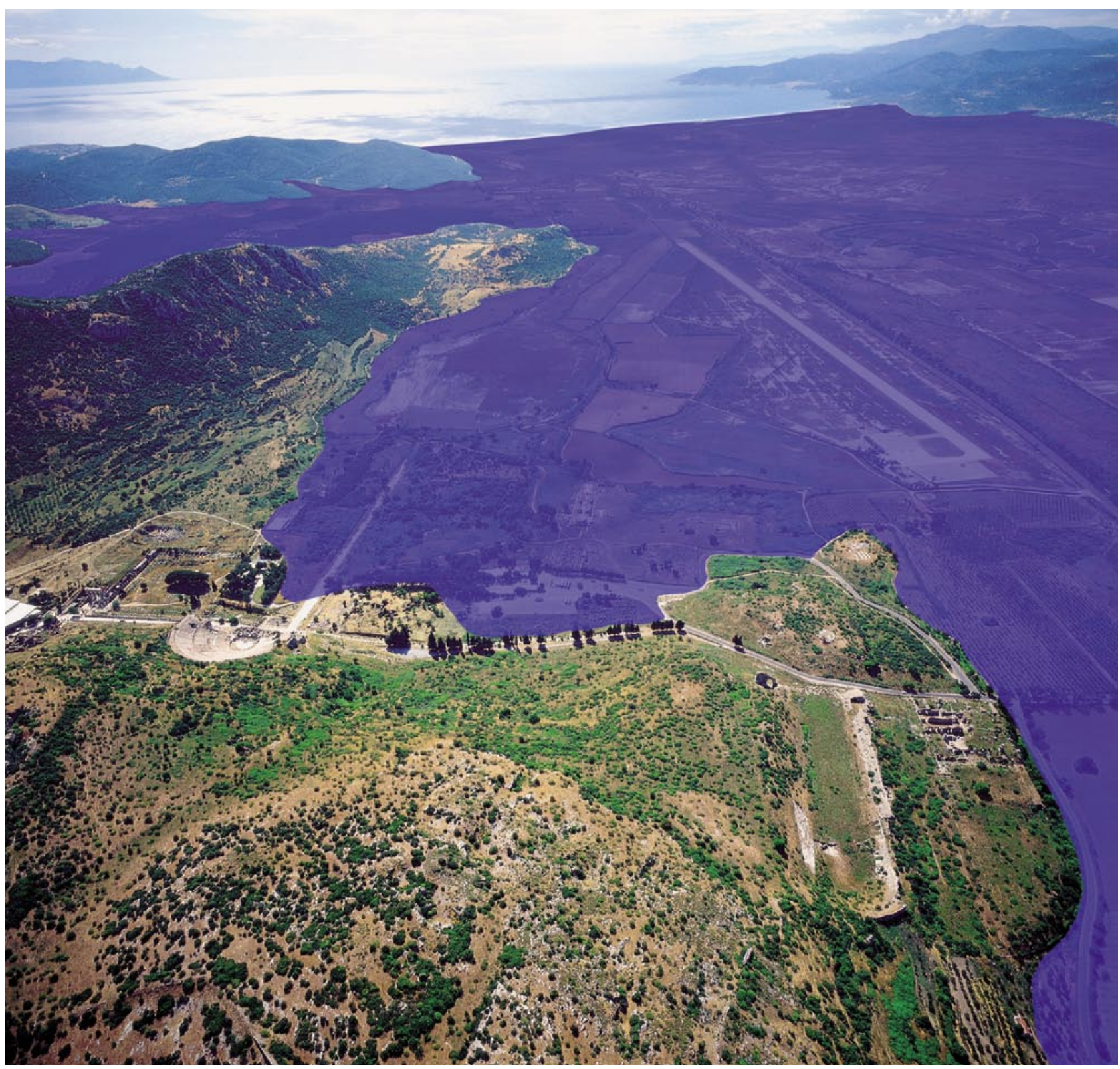

10 Luftbild von Osten über den Panayırdağ mit Rekonstruktion des ungefähren Küstenverlaufs in archaischer bis frühhellenistischer Zeit. Auf der Spitze der Tracheia (r.) ist der Felsspalttempel als heller Fleck erkennbar, ganz unten rechts die Hafenbucht von Koressos

Hafenthermen $^{78}$ (Abb. 11 Nr. 64) und im Norden der riesige Tempel für Hadrian als Olympios ${ }^{79}$ (Abb. 11 Nr. 73). Im mittleren 2. Jahrhundert erreichte die dichte Verbauung im Rahmen der Stadterweiterung auch die Hänge beim alten Koressos-Hafen, wo P. Vedius Antoninus in den Jahren nach 140 einen ThermenGymnasium-Komplex (Abb. 11 Nr. 81) errichten ließ ${ }^{80}$. Gegen Ende des 2. Jahrhunderts wurde über die

${ }^{78}$ Zuletzt allerdings wieder für eine einheitliche Bauausführung gemeinsam mit dem in domitianischer Zeit errichteten Gymnasiumsbereich: M. Steskal, Bemerkungen zur Funktion der Palästren in den ephesischen Bad-Gymnasium-Komplexen, ÖJh 72 , 2003, bes. 231.

${ }^{79}$ Karwiese, Koressos 214. 220 f. Taf. 9 f.; für die Zurückweisung der Kritik an dieser Bestimmung des Tempels vgl. P. Scherrer, Am Olympieion vorbei ...? Pausanias' Wegbeschreibung in Ephesos und der hadrianische Neokorietempel, in: Scherrer u. a., Steine 137-144.

${ }^{80}$ Aristeid. 2, 82. IvE 431. 438. 455; vgl. jetzt Steskal - La Torre (Anm. 33) bes. 221-244. 


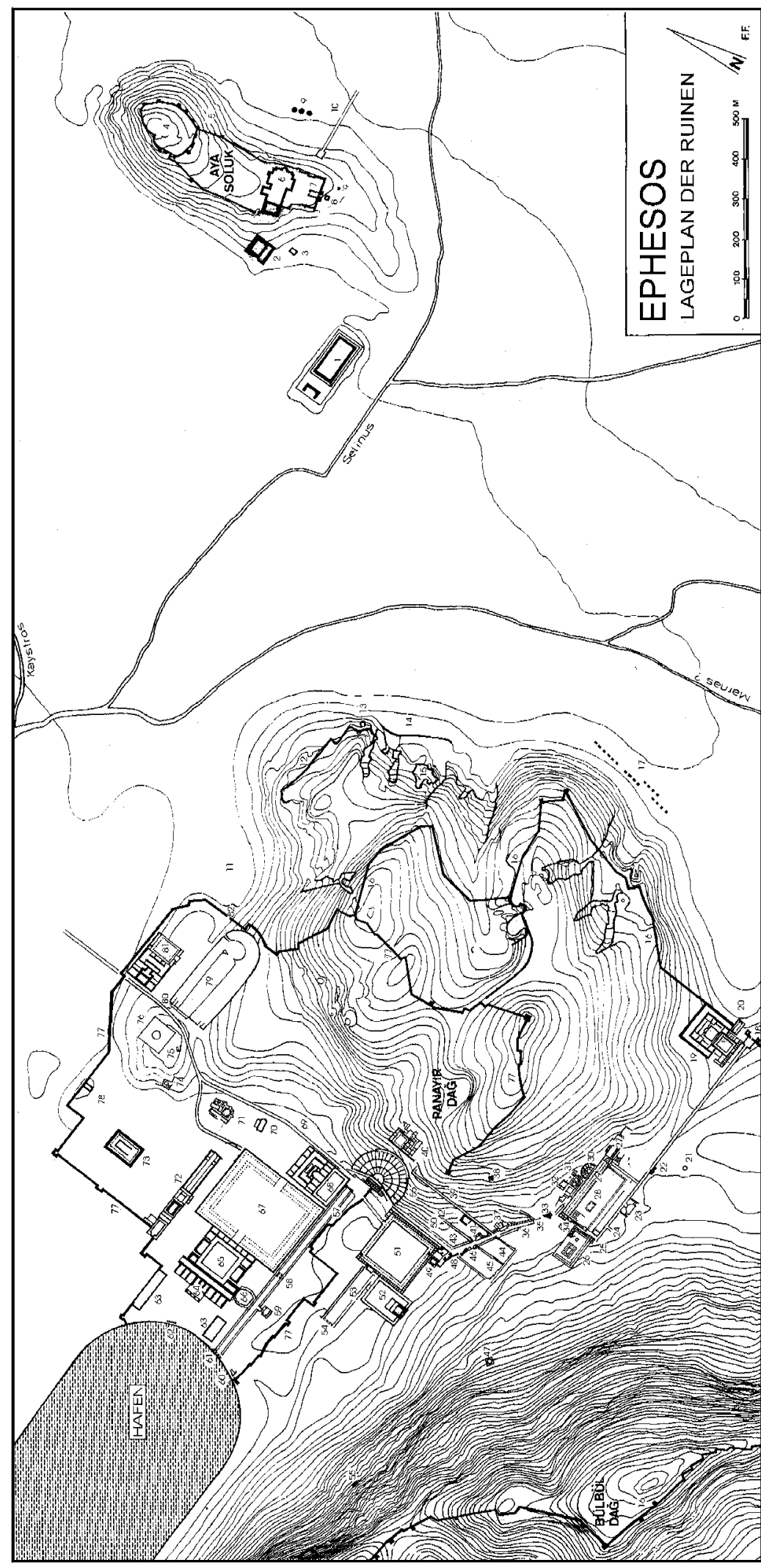

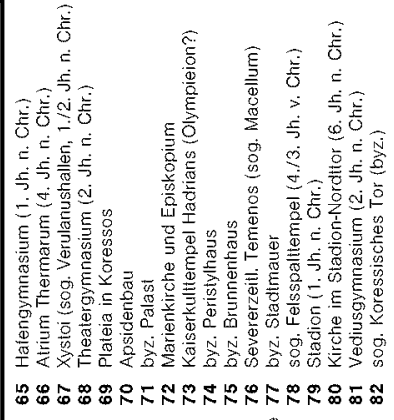

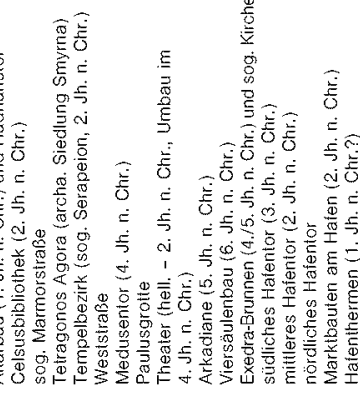

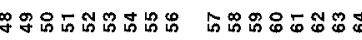

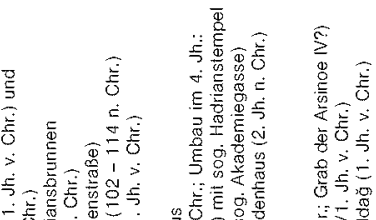

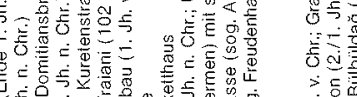
等

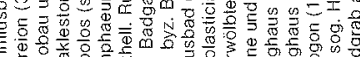

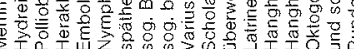

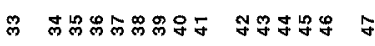

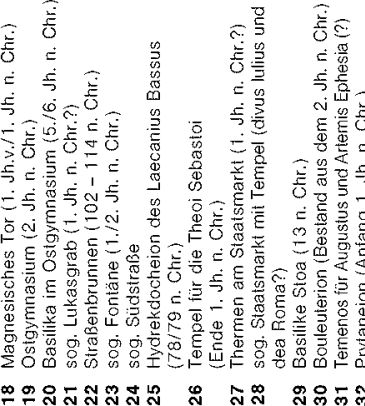

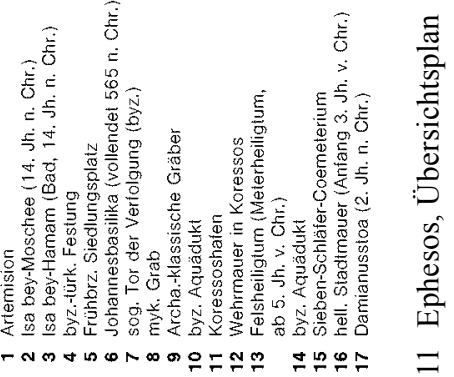


wohl immer noch sumpfige Ebene davor vom reichen Sophisten Flavius Damianus eine gedeckte Straße (Abb. 11 Nr. 17) als Direktverbindung vom Magnesischen Tor zum Artemision geschaffen ${ }^{81}$. Zu dieser Zeit hatte die Stadt ihren Zenit bereits überschritten, ab dem letzten Drittel des 2. Jahrhunderts ist keine Expansion mehr feststellbar, auch neue öffentliche Gebäude wurden anscheinend nur noch selten - und wenn, dann wohl im Zusammenhang mit dem Kaiserkult, - errichtet.

Zur Zeit des Kaiser Gallienus suchte ein schweres Erdbeben die Stadt heim, gefolgt von Plünderungen germanischer Seeräuber ${ }^{82}$. Ein umfangreicher Wiederaufbau scheint erst unter den Kaisern Theodosius I bis Theodosius II erfolgt zu sein, nach neuerlichen Erdbebenzerstörungen kam es unter Iustianian I zu einer letzten Blüte ${ }^{83}$. Bis in das beginnende 7. Jahrhundert $n$. Chr. blieb die Stadt in abnehmender Dichte der Besiedlung jedenfalls unverändert an ihrem Ort bestehen, dann enden fast alle bekannten städtischen Befunde in einer Brandschicht mit Münzen aus der Zeit des Phokas oder den frühen Jahren des Heraklios. Die darüberliegenden, in den Publikationen meist nur kurz erwähnten Evidenzen zeigen provisorischen und ärmlichen Charakter, gleichgültig, ob innerhalb oder außerhalb der sog. byzantinischen Stadtmauer. Diese ist anscheinend zu Beginn der Regierung des Heraklios entstanden, wohl in der Absicht, die bereits angesprochene Katastrophe zu verhindern, die aber doch bald darauf über Ephesos hereinbrechen sollte. Diese Stadtmauer (Abb. 2. 11 Nr. 77) umschloss nur noch einen kleinen Teil des ehemaligen Stadtgebiets, im Süden und im Osten, vom Hafen bis zum Kamm des Panayırdağ übernahm sie im Wesentlichen die Trasse der lysimachischen Mauer, von wo sie zum frühkaiserzeitlichen Stadion $^{84}$ herabstieg, das Vediusgymnasium umschloss und auf dem Weg zum Hafen zurück die Temenosmauern des bereits um $400 \mathrm{n}$. Chr. abgetragenen Olympieions benützte. Im Zentrum der so umwehrten Siedlung lag die als Bischofskirche ausgewiesene Marienkirche ${ }^{85}$, die in die Südstoa des Olympieion-Temenos eingebaut worden war (Abb. 9. 11 Nr. 72). Die frühbyzantinische Stadt lag also genau außerhalb der hellenistischen Gründung, östlich an diese angrenzend, mit ihrem Zentrum in der erst in der römischen Kaiserzeit dem Meer abgewonnenen Ebene.

Wie die endgültige Aufgabe dieser Stadt vor sich ging, lässt sich derzeit nur abschätzen. Die Ruinen der Marienkirche dienten noch bis etwa in das 13. Jahrhundert n. Chr. als Begräbnisplatz, die Siedlungsstrukturen in der Stadt scheinen aber im 9. Jahrhundert endgültig zu enden.

Der alte Burgberg der Bronzezeit hingegen dürfte ungefähr seit dem 7. Jahrhundert neu befestigt worden sein. Hier wurde über einem Grab und einer älteren Kirche vom Kaiserpaar Iustinian und Theodora kurz nach der Mitte des 6. Jahrhunderts n. Chr. eine prunkvolle Kuppelbasilika (Abb. 5-7. 11 Nr. 6) errichtet ${ }^{86}$, um Johannes Theologos zu ehren, von dem man bereits damals wohl annahm, dass er sowohl der Lieblingsjünger Jesu als auch der Evangelist und der Verfasser der Apokalypse gewesen sei ${ }^{87}$. Im 8. oder 9. Jahrhundert erfolgte die Aufwertung zur Bischofskirche, der Ort hieß nun nach seiner Hauptkirche Hagios Theologos, später im Türkischen vereinfacht zu Ayasoluk oder Ayasuluk ${ }^{88}$. Die Siedlung von Ephesos war unter dem Schutz des Hagios Theologos an jenen Punkt zurückgekehrt, wo ihre städtische Geschichte beinahe 4000 Jahre zuvor im Reich von Arzawa unter der Schirmherrschaft einer Potnia Aswiya begonnen zu haben scheint.

${ }^{81}$ Philostr. soph. 2, 23. Knibbe, Topographica Ephesiaca 207-211 Plan 1 (dort die ältere Lit.).

${ }^{82}$ St. Karwiese, Das Beben unter Gallien und seine anhaltenden Folgen, in: Lebendige Altertumswissenschaft. Festschrift Hermann Vetters (Wien 1985) 126-131.

${ }^{83}$ Zusammenfassung des Forschungsstandes zum 4. und frühen 5. Jh. aus städtebaulicher Sicht bei P. Scherrer, The City of Ephesos from the Roman Period to Late Antiquity, in: Koester, Ephesos 15-25; vgl. auch C. Steckner, Das spätjustinianische Episkopeion von Samos und die justinianische Bautätigkeit in Ephesos, in: Friesinger - Krinzinger, Forschungen 341-347. Speziell zu den nun nachvollziehbaren Bauvorgängen des späten 4. und mittleren 6. Jhs. n. Chr. in der Tetragonos Agora, P. Scherrer in: Scherrer - Trinkl, Agora 48-54.

${ }^{84}$ Zur Datierung des Stadions vgl. Scherrer, Topography 72.

${ }^{85}$ Das Baudatum der Marienkirche ist zuletzt kontrovers diskutiert worden; vgl. zuletzt St. Karwiese in: P. Scherrer (Hrsg.), Ephesus. The New Guide (Istanbul 2000) 180-183; Scherrer, Topography 80.

${ }^{86}$ M. Büyükkolanc1, Zur Bauchronologie der justinianischen Johanneskirche in Ephesos, JbAC Ergh. 20/1 (Münster 1995) 598-602; A. Thiel, Das Atrium der Johanneskirche, in: Friesinger - Krinzinger, Forschungen 485-490.

${ }^{87}$ H. Koester, Ephesos in Early Christian Literature, in: Koester, Ephesos, bes. 132 f. und 135-139.

${ }^{88}$ Zur Geschichte des Ortes in der Seldschuken- und Osmanenzeit immer noch wertvoll: C. Foss, Ephesus after Antiquity. A Late Antique, Byzantine and Turkish City (Cambridge, MA 1979). 


\section{Antike Topographie und geologische Forschung: Politik und Städtebau als Folge der maritimen und fluvialen Veränderungen}

Wie die Ausgrabungen im Bereich der hellenistisch-römischen Agora von Ephesos im Zusammenspiel mit geologischen Forschungen in den vergangenen 20 Jahren ergaben $^{89}$ (Abb. 13), war an der Stelle des späteren Agora-Westtores (Abb. 10. 12; Abb. 11 Nr. 51) noch im 6./5. Jahrhundert v. Chr. ein Strand mit einem mehr als $1 \mathrm{~m}$ unter dem heutigen liegenden Meeresspiegel. Häuser des vermutlich Smyrna genannten Dorfes aus dem späten 8. Jahrhundert v. Chr. wurden nur wenige Meter entfernt am auslaufenden Hang mit einem Fußbodenniveau von 0,70-0,90 m unter heutiger Meeresoberfläche angetroffen; die untersuchten küstennahen Häuser der Siedlung wurden nach mehrfacher Niveauerhöhung aber bereits im mittleren 6. Jahrhundert aufgegeben. Erst etwa 100 Jahre später wurde das Gelände auf einer Gehniveauhöhe von bereits etwa $0,90 \mathrm{~m}$ über heutigem Meeresspiegel für einen Gewerbebetrieb erneut genutzt. Anscheinend setzte damals an dieser Stelle schon die Verlandung ein und das Meer begann, trotz weiteren Anstiegs seines Wasserspiegels, zurückzuweichen. Bereits im frühen 3. Jahrhundert v. Chr. war es so weit entfernt, dass bei der Neugründung der Stadt durch König Lysimachos vom Platz des Agora-Westtores 0,60 m über dem heutigen Meeresspiegel eine Straße nach Westen - in die ehemalige Bucht hinein - geführt werden konnte, die aufgrund der fortschreitenden Verlandung und wegen des weiter steigenden Grundwasserspiegels ständig erhöht werden musste und etwa eineinhalb Jahrtausende später, wohl unter Kaiser Iustinianus I, eine Pflasterung in Höhe von ca. 3,5 m über (heutigem) Meeresspiegel erhielt.

In diesem Lichte betrachtet, ist auch der bisher hauptsächlich - wenn nicht ausschließlich - unter politischen Gesichtspunkten gesehene Synoikismos des Kroisos ${ }^{90}$ der Zeit um 560-550 v. Chr. neu zu interpretieren: Er zwang die in der Bucht in verschiedenen verstreuten Siedlungen lebenden Griechen, Lyder und Karer zum Bau einer gemeinsamen Stadt beim Artemision. Der Anstieg des Meeres führte, wie auch das oben erwähnte Beispiel am Agora-Westtor zeigt, damals wohl noch zu keiner wesentlichen Verlandung, sondern vielmehr zu einer Ausdehnung des Meeres mit dem Erreichen der äußersten historischen Küstenlinien $^{91}$ und somit zu der Überschwemmung küstennaher Anlagen, wobei vor allem die Hafenkais und ihre vorgelagerten Wellenbrecher außer Funktion gerieten. Der gemeinsame Bau eines neuen großen Hafens (Abb. 14 Nr. I) war in jeder Hinsicht ökonomischer und auch schneller durchführbar als die Sanierung und Höherlegung mehrerer kleiner Kaianlagen und der notwendigen Wellenbrecher, sofern dies aufgrund der topographischen Veränderungen überhaupt noch möglich gewesen wäre. Immerhin sollte Ephesos zum Haupthafen des aufstrebenden Lyderreiches, das sich gerade darauf vorbereitete, gegen den persischen Großkönig Kyros ins Feld zu ziehen, ausgebaut werden.

Um die vorhandenen Kräfte zu bündeln und einen langfristig funktionierenden Großhafen für militärische $^{92}$ wie wirtschaftliche Zwecke zu erhalten, musste aber die vorhandene lokale Bevölkerung auch langfristig geeint und mit einer gemeinsamen Identität ausgestattet werden. Dazu diente wohl die großzügige Förderung des Heiligtums der Artemis Ephesia durch Kroisos ${ }^{93}$. Die Planung und Ausführung eines neuen, in den Abmessungen viermal größeren Riesentempels - nach Plinius besaß er 127 Säulen und Außenmaße von $425 \times 225 \mathrm{Fu}^{94}$, also je nach Fußmaß um die $130 \times 70 \mathrm{~m}$, - anstelle des anscheinend gerade in Bau befindlichen sog. Tempels C (Außenmaße 33,30 × 16,35 m) ${ }^{95}$ mit architektonischer Bestausstattung, wie den laut Inschriften $^{96}$ teilweise von Kroisos selbst gestifteten columnae caelatae ${ }^{97}$, hob das Prestige der Schutzgöttin

${ }^{89}$ Brückner, Forschungen 44 f.; für einen ausführlichen archäologischen Situationsbericht und Kommentar vgl. P. Scherrer in: Scherrer - Trinkl, Agora, bes. 148 .

${ }^{90}$ Strab. 14, 1, 21.

${ }^{91} \mathrm{Vgl}$ dazu auch Brückner, Forschungen 50.

${ }_{92}$ Vgl. die bei Herodot 1, 27 überlieferte Episode, wonach Kroisos mit dem Bau einer Flotte zum Krieg gegen die vorgelagerten Inseln rüstete, das Vorhaben aber aufgab und Feundschaftsverträge schloss.

${ }^{93}$ Hdt. 1, 92

94 Plin. nat. 36, 21, 95-97.

${ }^{95}$ Bammer - Muss, Artemision 44; für einen Baubeginn vor König Kroisos nun Weißl, Kontextualisierung $194 \mathrm{f}$.

${ }^{96}$ IvE 1518 f.; Muss, Bauplastik, bes. 23 mit Abb. 1-3. 8; Bammer - Muss, Artemision 44 vermuten mit guten Gründen in Tempel C den vom Orakel in Delphi dem Tyrannen Pythagoras befohlenen Bau, vgl. dazu Suda s. v. Pythagoras, nach einer Geschichte des Baton von Sinope (FGrH 26 F 3).

97 Vgl. Hdt. 1, 92. 


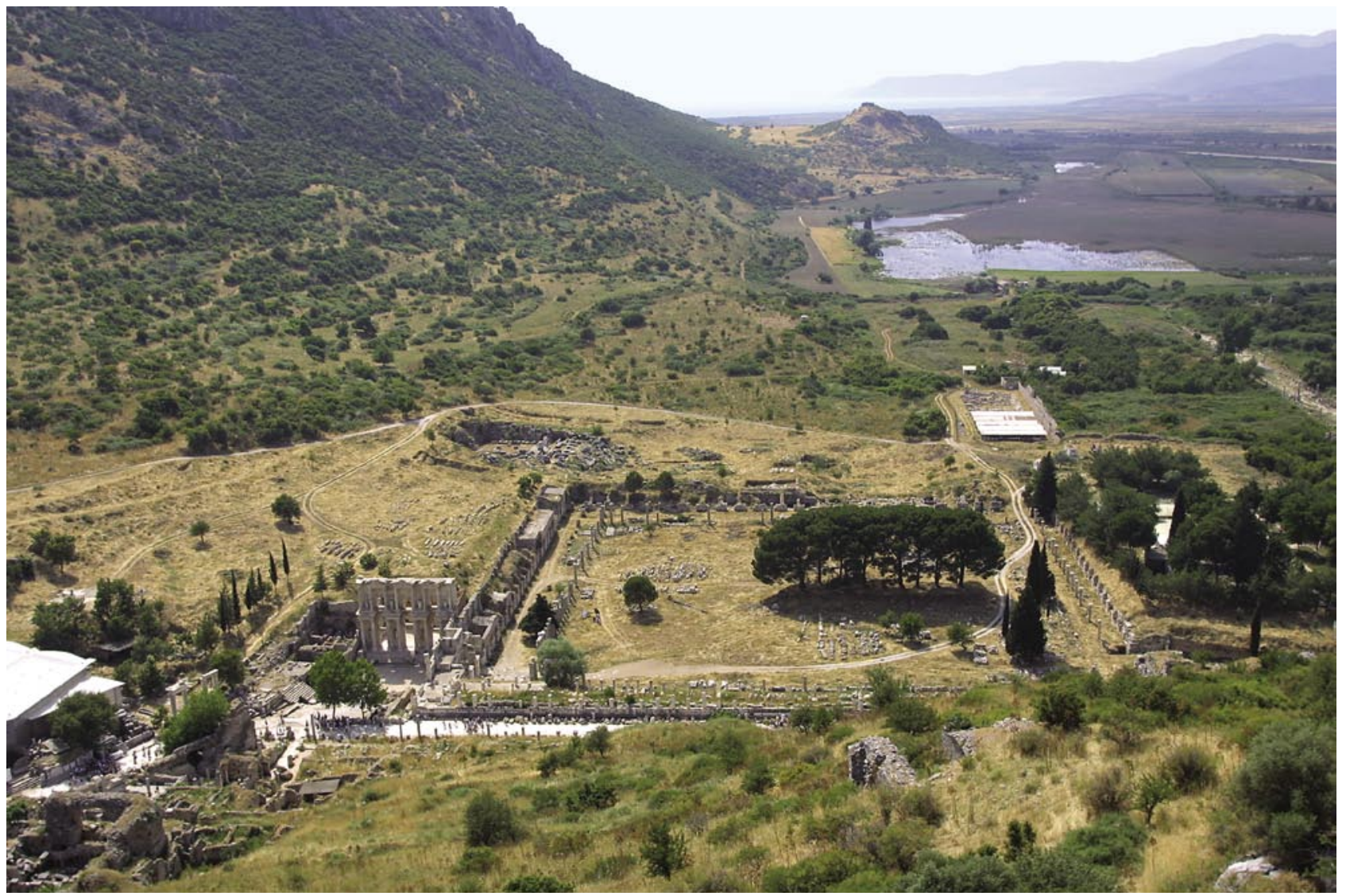

12 Blick vom Panayırdağ nach Westen auf die Tetragonos Agora, die Celsusbibliothek und die Ruinen des sog. Serapeions, dahinter das überschwemmte Hafenbecken

des Hafens und zog automatisch neue Kunden für den Handel der Stadt an. Der Tempel entwickelte sich immer mehr auch zu einem international respektierten Bankhaus, dem - wie das Beispiel des Söldnerführers und Schriftstellers Xenophon im 4. Jahrhundert zeigt ${ }^{98}$ - guten Mutes bedeutende Summen anvertraut werden konnten. Entscheidend für die Förderung der von den Griechen als Artemis Ephesia bezeichneten Göttin war aber wohl nicht nur ihre gegenüber der phrygischen Meter Oreia (Kybele) bessere Fernwirkung auf diese Bevölkerungsgruppe ${ }^{99}$, sondern wohl der in oder zumindest bei ihrem Asylbereich liegende Hafen. Außerdem ist nicht außer Acht zu lassen, dass vermutlich damals die bis in die beginnende Spätantike wirksame enge Verbindung ${ }^{100}$ zwischen den Stadtgöttinnen >Artemis von Sardes` und `Artemis von Ephesos geschaffen wurde, die natürlich auch eine enge wirtschaftliche Verflechtung der beiden durch eine direkte Straße verbundenen Städte - und die dabei vor allem beabsichtigte Ausschaltung von Smyrna als Handelskonkurrentin - symbolisierte. Es ging demnach also bei der Förderung der `Ephesia durch Kroisos auch um die innere Bindung von Ephesos an das Lyderreich und seine Hauptstadt Sardes, dessen Stadtgöttin >Artemis ja wohl auch nur eine der $`$ Ephesia< verwandte anatolische Gottheit gewesen sein kann ${ }^{101}$. Zur Bedeutung der Artemis Ephesia für und unter Kroisos im Zuge der Einrichtung eines »Staatskultes« und über ein beabsichtigtes Vernichten älterer Kulteinrichtungen für andere Gottheiten ist jüngst mit etwas spekulativen Interpretationen von Befunden aus dem Artemision nachgedacht worden, wobei sogar eine »an den Monotheismus semitischer Völker erinnernde Ausschließlichkeit der Verehrung« der Artemis behauptet worden ist ${ }^{102}$.

\footnotetext{
98 Xen. an. 5, 3, 6 .

${ }^{99}$ D. Knibbe in: Ephesos-Führer 16; Bammer - Muss, Artemision 41-44.

${ }_{100}$ Vgl. dazu etwa IvE 2 aus der 2. Hälfte des 4. Jhs. v. Chr., worin die Festgesandtschaft nach einem »alten Brauch« Chitone für die ephesische Artemis in Sardes holen sollte und in einem in Sardes »von Ephesiern eingerichteten Heiligtum« tätig waren.

101 Brenk, Artemis, bes. $164-167$.

102 Bammer - Muss, Artemision 42-44; kritisch dazu bereits Weiß1, Kontextualisierung.
} 


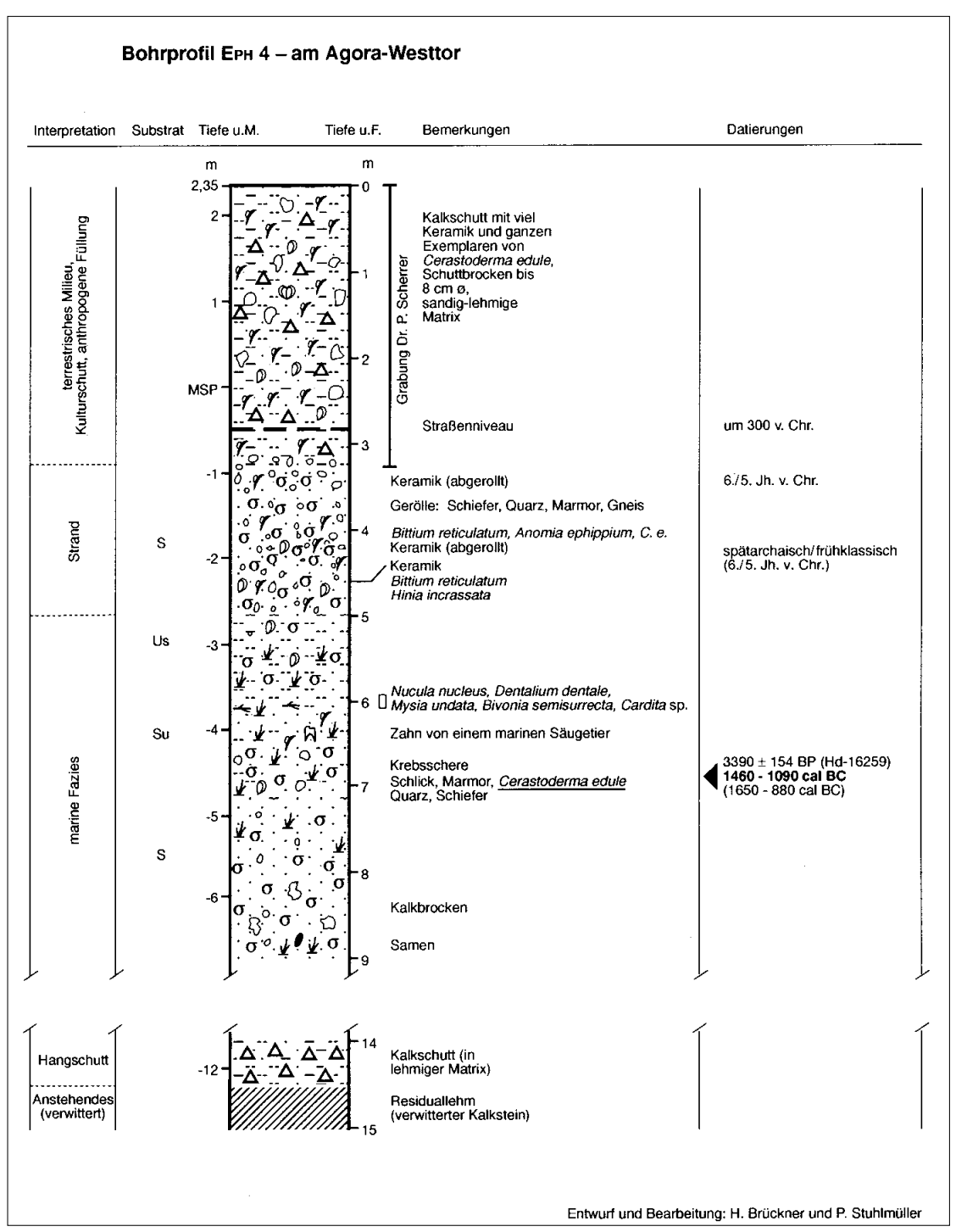

13 Bohrprofil EpH 4 an der Westseite des Westtores der Tetragonos Agora

Fest steht hingegen, dass die Hauptgöttin der griechischen Einwanderer nach dem Zeugnis Strabons Demeter war, deren Priesterschaft bei den Basiliden, den Nachkommen des angeblichen attischen Königssohns und Stadtgründers Androklos, bis $\mathrm{zu}$ seiner Zeit, also noch unter Kaiser Augustus, erblich war ${ }^{103}$. Noch Stephanos von Byzanz erzählt in seinem Lexikon unter dem Stichwort Koressos die Geschichte, dass Demeter hier mit ihrer Tochter spazieren ging und auf deren Frage nach dem Namen der Gegend geantwor-

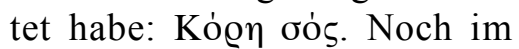
kaiserzeitlichen Prytaneion tagte außerdem ein Kultverband der

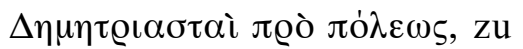
dem u. a. ein städtischer Priester der Artemis und eine Priesterin der Livia als Iulia Augusta Demeter Karpophoros gehör$\operatorname{ten}^{104}$. Mit dem Kult der Demeter, dem Fest der Thesmophorien, ist außerdem indirekt einer der schwerstwiegenden Fehler der Ephesier verbunden - die Ermordung der schiffbrüchigen Chier nach der Seeschlacht bei Lade im Jahre 494 v. Chr. ${ }^{105}$. Möglicherweise wegen dieser Mordtat durften die Ephesier das Apaturienfest nicht feiern, wie Herodot an anderer Stelle berichtet ${ }^{106}$.

Als Kroisos die Siedlung der Griechen belagerte, ließ der dortige Tyrann Pindaros, ein Neffe des Kroisos, die Stadt aber mithilfe eines 7 Stadien langen Seils mit dem Heiligtum der Artemis Ephesia verbinden und unterstellte sie damit dem Schutz dieser Göttin ${ }^{107}$. Daher muss einerseits Artemis damals bereits die unumstrittene Hauptgöttin und Herrin dieses Heiligtums gewesen sein, andererseits musste Pindaros natürlich bekannt sein, dass sein Onkel auf deren Verehrung größten Wert legte, hatte Kroisos doch schon vor Antritt seiner Regierung der Artemis Ephesia einen Besuch abgestattet und ihr eine bedeutende Weihung

\footnotetext{
103 Strab. 14, 1, 3.

${ }^{104}$ IvE 1595 (2. Jh. n. Chr.); IvE 4337 (tiberisch); dazu P. Scherrer, Anmerkungen zum städtischen und provinzialen Kaiserkult: Paradigma Ephesos Kaiserpriester - Entwicklungslinien von Augustus bis Hadrian, in: H. Thür (Hrsg.) »... und verschönerte

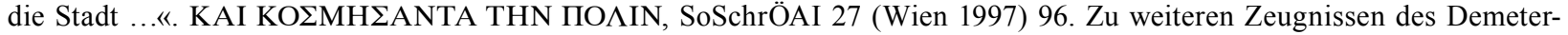
kultes aus der Kaiserzeit: D. Knibbe, Ephesos - Nicht nur die Stadt der Artemis, in: Studien zur Religion und Kultur Kleinasiens. Festschrift Friedrich K. Dörner II, EPRO 66 (Leiden 1978) 496 f.; R. E. Oster, Ephesus as a Religious Center under the Principate, I. Paganism before Constantine, in: ANRW II 18, 3 (Berlin 1990) 1671-1673.

${ }^{105}$ Hdt. 6,16

106 Hdt. 1, 147.

107 Hdt. 1, 26.
} 


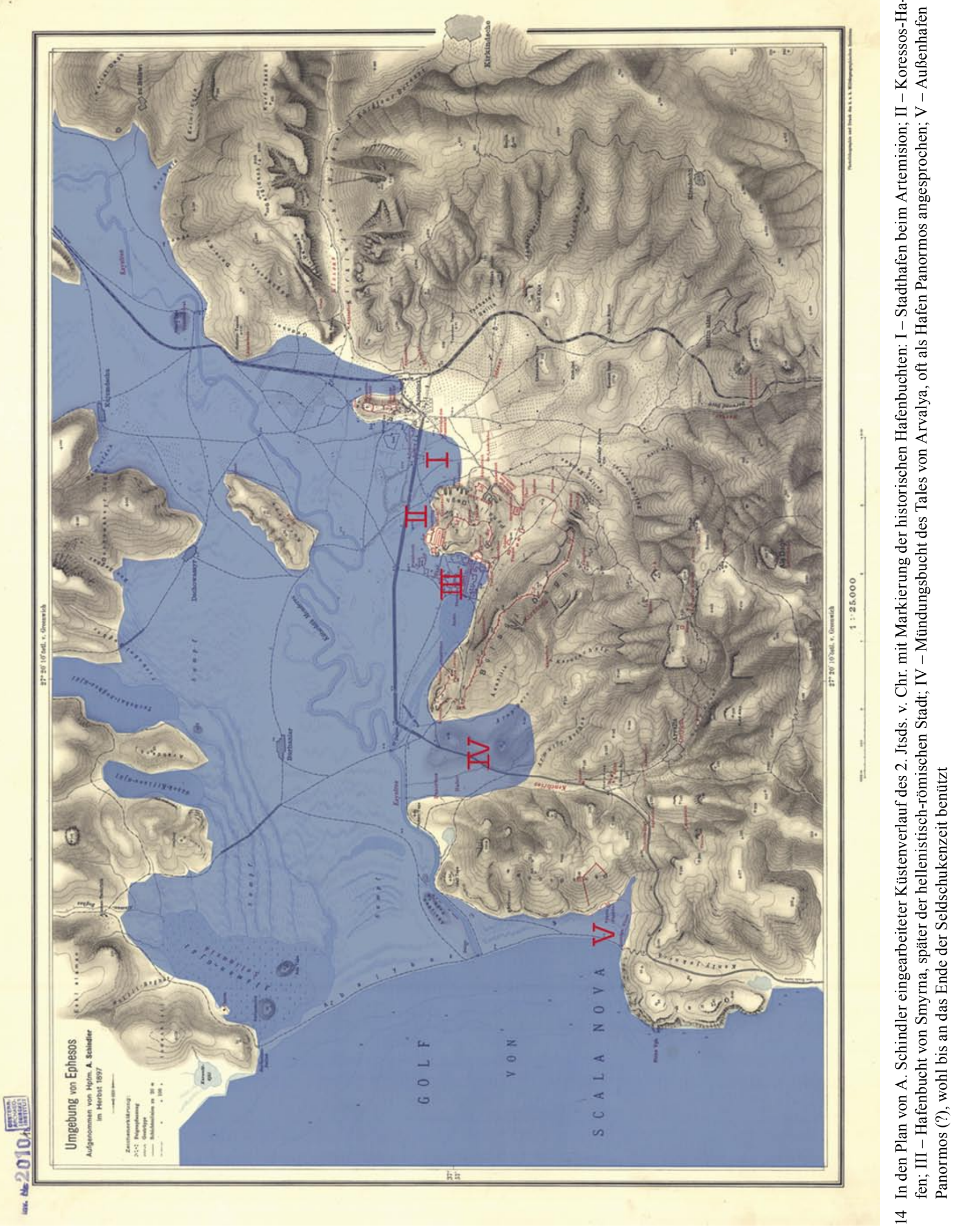


versprochen ${ }^{108}$. Die Anbindung der Griechen an die Göttin war also wörtlich zu nehmen und bedeutete nicht nur die Anerkennung der Oberhoheit und politischen Absichten des Kroisos im Allgemeinen, sondern symbolisierte wohl konkret die Zustimmung der Griechen zur geplanten Umsiedlung zum Artemision.

Als nächster Zeuge für die Veränderung der Landschaft durch die Gewässer ist zumindest indirekt

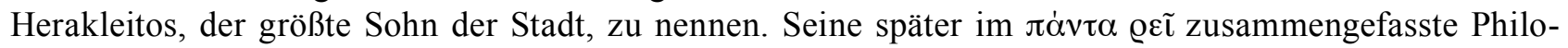
sophie vom »Fluss aller Dinge« entstand vermutlich nicht zum Wenigsten aus der Beobachtung des in Ephesos gebotenen Schauspiels, dessen Protagonisten einerseits das Land erobernde Meer und andererseits die Land aufschüttenden Flüsse waren. Wohl bereits zu seiner Zeit (um und bald nach 500 v. Chr.) setzten infolge der beginnenden Zurückdrängung des Meeres die Existenzprobleme seiner Vaterstadt ein, die bereits ein halbes Jahrhundert später Herodot verallgemeinernd anführen konnte ${ }^{109}$. Es könnte sein, dass die ionische Flotte sich 498 v. Chr. im - auch nach der Absiedlung der Griechen durch Kroisos anscheinend intakt gebliebenen - Koressos-Hafen auf der anderen Seite der Bucht (Abb. 2. 14 Nr. II) sammelte ${ }^{110}$, weil der Stadthafen am Artemision einfach zu klein war, man den Ephesiern nicht traute, oder diese die verbündeten Ionier einfach nicht in der Stadt haben wollten. Es könnte aber auch sein, dass bereits damals - insbesondere für Nichtortskundige - Schwierigkeiten bei der Zufahrt zum Stadthafen bestanden. Auch im Jahr 409 v. Chr. landete die athenische Expeditionsflotte unter Thrasyllos zum Angriff auf Ephesos im Hafen Koressos ${ }^{111}$. Dies geschah aus taktischen Gründen: Der Stadthafen war ja wohl gesperrt und wäre zumindest verteidigt worden. Das für uns Interessante an der Nachricht ist, dass es diesen Hafen weiterhin gab, bzw. er auch noch 150 Jahre nach Aufgabe der Griechenstadt in einem benützbaren Zustand und so groß war, dass die gesamte Kriegsflotte in ihm vor Anker gehen konnte. Der Koressos scheint demnach immer wieder als Ausweichhafen benützt worden zu sein, was auf Schwierigkeiten mit dem Haupthafen der Stadt beim Artemision deuten könnte.

Nur ein halbes Jahrhundert später musste die Priesterschaft für das Heiligtum der Artemis Ephesia die notwendigen Konsequenzen aus dem weiterhin ansteigenden Meeresspiege ${ }^{112}$ ziehen. Gleichgültig, ob der angeblich durch Herostratos in der Geburtsnacht Alexanders d. Gr. im Jahr 356 v. Chr. ausgelöste Brand des Tempels der Frevel eines Wahnsinnigen ${ }^{113}$ oder - wie zuletzt angenommen wurde - die Folge eines Blitzschlages war ${ }^{114}$, als Artemis Ephesia angeblich gerade Olympias bei der Geburt des künftigen Weltherrschers beistand: Für das Haus der Göttin kam das Unglück gerade rechtzeitig, sollte es nicht im Alluvium versinken (Abb. 7). Der Neubau des Tempels, der in Wirklichkeit nur von außen wie ein geschlossener Baukörper wirkte, tatsächlich aber ein von Mauern und überdachten Säulenreihen umgebener Hof (Sekos) war, erfolgte genau über den alten Fundamenten, jedoch auf einem 2,76 m höheren Niveau, wofür aufgrund des notwendigen breiteren Stufenbaus eine deutliche Verkleinerung der freien Hoffläche zwischen dem zentralen Naiskos und den Sekosmauern in Kauf genommen wurde ${ }^{115}$.

Um 300 v. Chr. war die Situation von Ephesos dann endgültig unhaltbar geworden. Der neue Stadtherr Lysimachos verlegte die Siedlung kurzerhand um $3 \mathrm{~km}$ bzw. zwei Buchten meerwärts nach Westen (Abb. 14 Nr. III). Die bei Strabon 14, 1, 21 erzählte Geschichte, der König habe bei Regen die Kanäle der alten Stadt verstopfen lassen, um die Ephesier zur Übersiedlung zu zwingen, besitzt antilysimachische Tendenz, aber

\footnotetext{
${ }^{108}$ Hdt. 1, 92. Ausführlich auch: Nikolaos von Damaskus, FGrH 90 F 65; Ail. var. 4, 27; Suda s. v. Kroisos; vgl. dazu Muss, Bauplastik $26 \mathrm{f}$.

109 Hdt. 2, 10.

${ }^{110}$ Hdt. 5, 100.

111 Xen. hell. 1, 3, 1-10; Diod. Sic. 13, 64, 1. Vgl. auch den Papyrus bei: G. A. Lehmann, Ein neues Fragment der Hell. Oxy., ZPE 26, 1977, 181-191; H. Wankel, Sprachliche Bemerkungen zu den neuen Fragmenten der Hellenica Oxyrhynchia, ZPE 29, 1978, $54-56$.

112 Vgl. dazu bereits, wenn auch natürlich noch ohne die heutigen geologischen Detailinformationen: A. Bammer, Zum jüngeren Artemision von Ephesos. Die Terrasse des jüngeren Artemisions und eustatische Schwankungen des Meeresspiegels, ÖJh 47, 1964/1965, 126-131.

113 Vgl. z. B. Plut., Alexander 3, 3; Solin. 183, 23; Val. Max. 8, 14.

114 Karwiese, Artemis $57 \mathrm{f}$.

115 A. Bammer - U. Muss in: Ephesos-Führer 54.
} 
auch einen wahren Kern, wie bereits D. Knibbe festgestellt hat ${ }^{116}$. Tatsächlich hatten wohl eher die Flüsse und Bäche das die Stadt umgebende Land erhöht, das Regenwasser konnte nicht mehr ins Meer abfließen und der steigende Meeresspiegel drückte das Wasser aus den Kanälen wieder an die Oberfläche zurück.

Jüngste geologische Bohrungen bestätigen die Angabe des Plinius, dass der Hügel Syrie (heute Korudağ), $1,8 \mathrm{~km}$ nordwestlich des Artemisions, einst eine Insel gewesen sei ${ }^{117}$, und präzisieren die Zeitspanne, in der die vom Kaystros verursachte Anschwemmung die Syrie erreichte, in das frühe 2. Jahrhundert v. Chr. (Abb. 4). Spätestens um die Mitte des 1. Jahrhunderts v. Chr. war der Bereich um die Syrie völlig verlandet. Wie progressiv die Ablagerung des Alluviums hier vor sich ging, zeigt die ${ }^{14} \mathrm{C}$-Analyse von Materialien aus den Bohrkernen: Im 6. Jahrtausend v. Chr. betrug die Wassertiefe bis zu $30 \mathrm{~m}$, im 7./6. Jahrhundert v. Chr. war das Meer hier immerhin noch über $15 \mathrm{~m}$, um $400 \mathrm{v}$. Chr. etwa $12 \mathrm{~m}$ tief gewesen ${ }^{118}$.

Die Probleme der Kroisos-Stadt und des Artemisheiligtums resultierten aber nicht aus den Anschwemmungen des Kaystros, sondern aus den von Süden zur Küste herabführenden kleineren Flüssen ${ }^{119}$. Diese geologische Erkenntnis gewinnt noch eine zusätzliche Stütze im heutigen Oberflächenrelief der Landschaft, welches von Süden nach Norden zu ein nicht unbeachtliches Gefälle aufweist. Wäre die Sedimentation vom Kaystros aus erfolgt, müsste die Höhenschichtlinie bei diesem zumindest gleich hoch liegen wie im Bereich des Artemisions ${ }^{120}$. In der Nähe des Artemisheiligtums mündete der in mehreren literarischen Quellen bezeugte Fluss Selinus (Abb. 1. 4). Bereits Xenophon ${ }^{121}$ und Archestratos von Gela ${ }^{122}$, ein Zeitgenosse des Aristoteles, rühmten die im brackigen Wasser des Selinus lebenden Fische.

Strabons Beschreibung der Küste in geographischer Folge von Süden nach Norden fährt fort ${ }^{123}$ : »Nächst der Mündung des Kaystros liegt ein See, der sich aus dem Meer ergießt, Selinusia genannt, und mit diesem fließt ein anderer, dahinterliegender zusammen; beide bringen große Einkünfte.« Es folgt hierauf die wirtschaftsgeschichtlich interessante Erörterung der Rechtsstreitigkeiten um diese Fischereieinkünfte zwischen den pergamenischen Königen bzw. später den römischen Steuerpächtern und den Ephesiern. Damit ist klar, dass diese topographische Situation zumindest in das frühe 2. Jahrhundert v. Chr. zurückreicht.

Im Sinne des strabonischen Periplus entlang der Küste von Süden nach Norden sollte nach herkömmli-

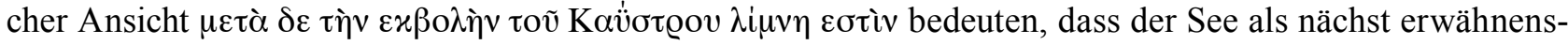
werter Punkt folgt, nachdem man den Kaystros überschritten hat. Die Annahme einer Lage der Lagune rechts bzw. nördlich des Kaystros, der knapp südlich der Syrie fließt, lässt nur eine Situierung der Seen nördlich oder westlich der Syrie zu, da zwischen ihrer Südseite und dem Kaystros kein Platz für ein wirtschaftlich bedeutendes Gewässer ist. So wird der Text bisher auch einheitlich verstanden: Strabon müsse eine Lagune gemeint haben, als deren Reste die auf der von A. Schindler 1898 verfassten Karte (Abb. 1) eingezeichneten Seen und die Restlagune ganz im Norden der ephesischen Bucht rund um den Adatepe bis heute figurieren ${ }^{124}$.

Allerdings hielte ich es für ratsam, die Selinusia wesentlich weiter landeinwärts zu suchen, am ehesten im Gebiet zwischen dem Ayasuluk und der Syrie. Wie sich aufgrund der geologischen Untersuchungen gezeigt hat, hat der Kaystros seine Mündung im 2. Jahrhundert v. Chr. bis zur Syrie vor- oder gar über diese hinausgeschoben. Damit könnte er südlich der Syrie an seiner eigenen Südseite einen Wall aufgeschüttet haben, so wie die vom Süden heranführenden Flüsse einen Damm im Westen und Norden ihrer Mündungen ausbildeten. Dies sind die üblichen Mechanismen einer Deltabildung sich verlangsamender Flüsse, wie sie

\footnotetext{
${ }^{116}$ D. Knibbe in: Ephesos-Führer 20; vgl. auch bereits Benndorf, Ortskunde 89.

117 Plin. nat. 5, 115.

118 Brückner, Forschungen 42-44.

${ }^{119}$ Kraft u. a., Environs 128-132.

${ }^{120}$ Eintragungen auf der Karte von A. Schindler, Beilage zu FiE 1 (Wien 1906), hier Abb. 1: Höhenkote T $=15,0 \mathrm{~m}$ knapp $600 \mathrm{~m}$ südsüdöstlich vom Artemision; $\mathrm{T}^{\mathrm{a}}=10,4 \mathrm{~m}$ ca. $300 \mathrm{~m}$ südlich des Artemisions; $\mathrm{T}^{\mathrm{a}}=6,5-7 \mathrm{~m}$ ca. 400 westlich des Artemisions; die Höhe des Kaystros nördlich des Artemisions liegt jedoch nur zwischen 2 und $3 \mathrm{~m}$ über dem Meer.

${ }_{121}$ Xen. an. $5,7$.

${ }_{122}$ Archestrat. Gel. fr. 143 (ed. H. Lloyd-Jones - P. Parsons, Supplementum Hellenisticum [Berlin - New York 1983]).

${ }_{123}$ Strab. 14, 1, 26.

${ }^{124}$ Benndorf, Ortskunde 69 Anm. 3 und S. 73.
} 
J. C. Kraft, İ. Kayan und H. Brückner für die ephesische Bucht nachgezeichnet haben (Abb. 4). Eine oder nach Strabon auch mehrere Lagunen mussten demzufolge zwischen der Westseite des Ayasuluk bzw. dem Artemision, der Südseite der Syrie bzw. südlich des an ihr vorbeifließenden Kaystros und der Nordflanke des Panayırdağ entstehen. Strabon kann nur diese Lagunen gemeint haben. Tatsächlich lässt $\mu \varepsilon \tau \grave{c} \delta \grave{\varepsilon} \tau \grave{\eta} v$

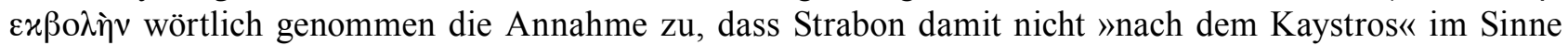
der Reiserichtung ausdrücken wollte, sondern »hinter der Mündung des Kaystros« meint. Nach Strabons Angabe genügte offensichtlich die geringe Meeresspiegelschwankung zwischen Ebbe und Flut, um Meerwasser in die Lagune gelangen zu lassen, die sich solchermaßen landeinwärts ausbreitete.

Auf eine generelle Erhöhung des Grundwasserspiegels und eine regelrechte Überflutung ehemaligen Landes weist auch sein abschließender Hinweis zur Lagune Selinusia, wenn Strabon angibt, dass an ihrer tiefsten Stelle das Heiligtum eines Königs stünde; angeblich sei Agamemnon dessen Erbauer gewesen ${ }^{125}$.

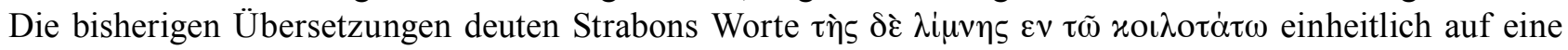
Lage des Heiligtums im innersten Winkel des Sees, also an seinem abgelegensten Ufer. Als beste Parallele meiner Interpretation sei hier jedoch der $\varkappa 0 \tilde{\lambda} \lambda \mathrm{\varsigma} \varsigma \pi 0 \tau \alpha \mu$ ó $\varsigma$ bei Polybios 31, 37, 4 angeführt, wo unzweifelhaft auf ein tiefes Flussbett Bezug genommen wird.

Diese sagenverdächtige Bemerkung über ein von einem homerischen Heerführer gegründetes Heiligtum $^{126}$ »am Grunde eines Sees« könnte für ein schon im ausgehenden Hellenismus als uralt angesehenes Küstenheiligtum tatsächlich zutreffend sein, wenn man die nachweisliche ständige Erhöhung des Meeresspiegels gegenüber dem Land und den Grundwasseranstieg durch die Sedimentierung der Flüsse in Betracht zieht. Andererseits mag die Zuschreibung des Heiligtums an Agamemnon zumindest bedeuten, dass seine Gründung von Strabons (spät-)hellenistischer Quelle in mykenischer Zeit angesetzt worden war, in der die Besiedlung des Ayasuluk und die Anwesenheit von Mykenäern nachweisbar sind. Deshalb könnte man - soweit man derartige Sagen überhaupt als historische Quellen zulässig findet - am ehesten davon ausgehen, dass das in der Lagune versunkene Heiligtum einst am Küstenstreifen am Fuß des Ayasuluk an der Mündung des Selinus situiert war, wie das durch Ausgrabungen bekannte Artemision des 1. Jahrtausends v. Chr., allerdings - entsprechend dem damaligen Niveau des Meeresspiegels - etwas oder sogar deutlich weiter im Osten von diesem, je nachdem, wie sanft oder steil der Küstenbereich hier verlief. Damit könnten wir einen Hinweis auf die Lage eines Vorgängerheiligtums in mykenischer, oder besser, in luwischer Zeit, als hier das Reich von Arzawa bestanden hatte, gewonnen haben. Der steigende Meeresspiegel im 2. und 1. Jahrtausend v. Chr. führte zu seiner Überflutung und einer Verlegung des Kultplatzes landeinwärts. Tatsächlich konnte im zentralen Bereich des Artemisheiligtums unter den ältesten Tempelbauten zwar vereinzelt ein Stratum mit ausschließlich mykenischen Funden entdeckt werden, dann aber ist erst wieder, wie oben ausgeführt, eine kontinuierliche und wohl von nun an kultische Nutzung des Areals aus der Zeit ab dem Ende des 2. Jahrtausends v. Chr. nachweisbar ${ }^{127}$.

Die Angabe bei Plinius, Ephesi ubi [sc.: mare] quondam aedem Dianae adluebat ${ }^{128}$, dass also das Artemision ursprünglich direkt am Meer gelegen sei ${ }^{129}$, wurde durch geologische Bohrungen von J. Kraft und İ. Kayan bestätigt ${ }^{130}$. Das Meer erreichte bei seiner maximalen Ausdehnung durch den ansteigenden Wasserspiegel im 1. Jahrtausend v. Chr. ungefähr die Stelle des großen Altarbaus westlich des Tempels.

\footnotetext{
${ }_{125}$ Strab. 14, 1, 26.

126 Auch die Gründung von Pygela bzw. des dortigen Tempels der Artemis Munychia wird bei Strab. 14, 1, 20 auf Agamemnon zurückgeführt.

${ }^{127}$ Vgl. o. bei Anm. 24-27.

128 Plin. nat. 2, 201.

129 Aufbauend auf die Notizen des Plinius zum Artemision entwickelte St. Karwiese, Gedanken zur ältesten Geschichte von Ephesos, in: X. Türk Tarih Kongresi'nden ayrıbasım (Ankara 1990) 646 f., folgenden rein hypothetischen Gedankengang: Die Angaben bei Plinius bezögen sich auf eine Zeit, als das Artemision noch an einer anderen Stelle, etwa weiter nordöstlich bei der Insel Syrie, gelegen habe. »Der Name `Selenuntes〈 bezöge sich dann auf die Flußschleife, die einen mondförmigen Umriß gehabt bzw. an zwei gegeneinander gekehrte Halbmonde erinnert haben mag. « Da die Überlieferung des Fluss- bzw. Lagunennamens aber einheitlich Selinus/Selinusia lautet, ist eine Zusammenhang mit Selene (Mond) abzulehnen. Der an mehreren

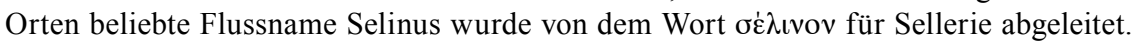

${ }^{130}$ Kraft u. a., Environs.
} 
Gleichzeitig ergibt sich aber daraus auch ein Hinweis auf die schwer verständlichen Besitzverhältnisse in Ephesos noch in hellenistisch-römischer Zeit. Bisher hat sich, soweit ich sehe, niemand die Frage gestellt, wieso die Lagune - und später das aus ihr wieder zurückgewonnene Land, wie die augusteischen Vermessungsurkunden, von denen eine vier Stadien entfernt vom Artemision in Richtung auf das Magnesische Tor zu von J. T. Wood gefunden wurde ${ }^{131}$, - eigentlich der Artemis Ephesia gehörte, und nicht dem Demos der Stadt oder Privaten. Der ausgedehnte Grundbesitz der Artemis könnte teilweise mit der Geschichte bei Strabon erklärt werden, wenn es sich bei dem Tempel »am Grunde des Sees« sozusagen um das älteste Artemision handelte.

Die mögliche Ausdehnung der Lagune in hellenistischer Zeit lässt sich anhand der Rekonstruktion der Landschaft aus geologischer Sicht von J. Kraft und seinen Kollegen erkennen. Sie reichte wohl anfangs von der westlichen Grenze des Artemisheiligtums bis zum Koressischen Hafen an der Nordflanke des Panayırdağ und verschob sich dann mit zunehmender Verlandung immer weiter nach Westen (Abb. 4). Die bereits angesprochenen Seen im Norden der Bucht und der zusätzliche, noch auf der Karte von A. Schindler (Abb. 1) eingezeichnete Sumpf ganz im Nordwesten der Bucht sind die jüngsten Nachfolger der Selinusia im Zuge der historischen Verschiebung des Kaystrosdeltas.

Zur angesprochenen Ausdehnung der Selinusia in frühhellenistischer Zeit passt auch, dass ab dem 4. Jahrhundert v. Chr. der Koressos-Hafen nicht mehr in den Quellen aufscheint. Dafür nennt Kreophilos

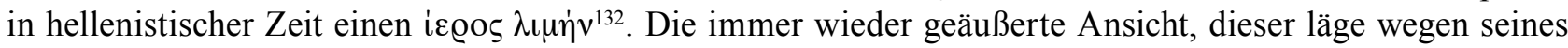
Namens beim Artemision ${ }^{133}$, ist sicher falsch. Kreophilos gibt die Lage des »heiligen Hafens « eindeutig bei der Stadtquelle Hypelaios im Gebiet der Tracheia an. Es dürfte sich also entweder um einen Hafen handeln, der zur Überfuhr von der Tracheia über die in hellenistischer Zeit bestehende Lagune Selinusia zum Artemision bzw. als Fischereihafen für die Bewirtschaftung des bezeugten Fischreichtums diente ${ }^{134}$, oder um einen hellenistischen Hafen an der Westseite der Tracheia, der wegen seiner durch eine Festung zusätzlich geschützten Lage als Kriegshafen gedient haben könnte ${ }^{135}$ und vielleicht deswegen seinen euphemistischen Namen erhalten hatte. Vielleicht wollte Kreophilos allerdings mit der Bezeichnung »heiliger Hafen« auch nur auf den vermuteten Landeplatz des Androklos anspielen und gab so dem Koressos-Hafen eine prestigeträchtige Bezeichnung.

Mit der Annahme einer Lagune, die aus dem Fluss Selinus gespeist wurde, erklärt sich auch eine bisher schwer zu verstehende Stelle bei Plinius ${ }^{136}$. Dieser schreibt - im Gegensatz zu dem sonst allein genannten Fluss - ... et templum Dianae complexi e diversis regionibus duo Selinuntes, womit er große Verwirrung in der Wissenschaft ausgelöst hat. Bereits O. Benndorf stellte sich dem Problem ${ }^{137}$ : $\gg$ Man hat hier früher an eine Verwechslung mit den selenusischen Seen gedacht, die zwei Stunden entfernt vom Artemision lagen. Aber schon der sprachliche Ausdruck kann bei Plinius nur auf Bäche gedeutet werden.« Im Weiteren kam Benndorf, wie gleichzeitig auch L. Bürchner ${ }^{138}$, zur Überzeugung, dass zwei von Osten bzw. Südosten kommende Wasserläufe das Artemision umflossen hätten ${ }^{139}$. Dies mag zwar theoretisch als möglich erachtet werden, als besonders wahrscheinlich möchte man einen solchen Bachverlauf aber nicht bezeichnen, müssten doch dann auf kürzester Distanz in der Schwemmlandebene zwei Bachbette eingegraben gewesen sein. Wir wissen allerdings nichts über das genaue Geländerelief der griechischen Zeit, da die Landschaft, wie die Ausgrabungen am Artemision gezeigt haben, durch die Flussanschwemmungen in diesem Areal seither um bis zu $8 \mathrm{~m}$ erhöht worden ist.

${ }^{131}$ IvE 1522.

132 Zitiert bei Athen. 8, 62 p. $361 \mathrm{c}-\mathrm{e}=\mathrm{FGrH} 417 \mathrm{~F} 1$.

133 Zuletzt Kraft u. a., Analysis $187 \mathrm{f}$.

${ }_{134}$ Vgl. Archestratos Gel. fr. 143; Strab. 14, 1, 26. Vgl. dazu Scherrer, Siedlungsgeschichte 384.

135 Scherrer, Topography 63-66.

136 Plin. nat. 5, 115.

137 Benndorf, Ortskunde 69 mit Anm. 3.

${ }_{138}$ RE V (1905) 2783 s. v. Ephesos Nr. 1 (Bürchner).

139 Ähnlich auch M. Kerschner, Ein stratifizierter Opferkomplex des 7. Jh.s aus dem Artemision von Ephesos, ÖJh 66, 1997, Beibl. 92 f., der allerdings die Situation des 7. Jhs. v. Chr. mit einer möglichen Deltamündung beiderseits des Kultplatzes mit der viel späteren, bei Plinius beschriebenen Situation vermischt. 
In den meisten Landkarten und Abhandlungen seit O. Benndorfs Analyse der antiken Landschaft wird der (heute) bedeutendere und westliche dieser Wasserläufe, der fast genau nach Norden fließende Dervend Dere, als Marnas bezeichnet ${ }^{140}$. Dieser Name ist aus zahlreichen ephesischen Inschriften und Münzen seit domitianischer Zeit für den Quellfluss einer Wasserleitung bekannt. Die im Jahr 92/93 n. Chr. eingeweihte Marnasleitung kann aber nicht mit der augusteischen Aqua Throessitica, deren von Sextilius Pollio erbaute Aquäduktbrücke das für den Marnas beanspruchte Flusstal quert, identisch $\operatorname{sein}^{141}$, sondern wurde anscheinend vom Fluss mit dem heutigen Namen Değirmen çay aus den Bergen südöstlich von Kuşadası entlang der Küste in die römische Stadt geführt ${ }^{142}$. Dieser Wasserlauf dürfte aber schon in der Antike seine Mündung zu weit im Westen gehabt haben, als dass er im Bereich des Heiligtums münden hätte können; sein Alluvium beeinträchtigte die archaisch-klassische Stadt aber wohl am meisten.

Etwas östlich von diesem kleinen Fluss kommt aus den Bergen herab ein weiterer Bach in nordwestlicher Richtung genau an der Südspitze des Ayasuluk vorbei auf das Artemision zu. Sein Bachbett könnte bei den Ausgrabungen unter dem östlichsten Teil des Tempels der Kroisoszeit angeschnitten worden $\operatorname{sein}^{143}$. Diesen Bach meinen zweifellos auch die im Zuge der augusteischen Restauration des Artemisions ${ }^{144}$ von den Vermessern 6/5 v. Chr. gesetzten Inschriften ${ }^{145}$. Das damals wohl nicht nur vermessene, sondern zuvor neu gefasste Flussbett wies eine Breite von 15 Ellen (bei Annahme der allgemein üblichen Maßgröße $6,60 \mathrm{~m}$ ) auf.

Nach der im Voranstehenden gegebenen Analyse der Quellen kann - trotz aller Unsicherheiten und anderweitig geäußerten Bedenken - Plinius mit den beiden Selinuntes, die den Tempel aus verschiedenen Richtungen umflossen, nur einerseits die Lagune im Nordwesten und andererseits den Fluss im Süden oder Südosten gemeint haben, die jeweils aus einer anderen Richtung auf das Artemision zuströmten.

Welcher der nahen Bachläufe allerdings nun der bei Xenophon genannte Selinus ist, kann nicht mit einiger Sicherheit bestimmt werden. Am ehesten möchte man mit O. Benndorf und A. Schindler (Abb. 1) den kleinen Wasserlauf, der aus dem Tal nördlich des Tavşantepe in direkter Westrichtung auf das Artemision zuströmt, mit diesem Namen versehen. Damit wäre auch den diversis regionibus, den entgegengesetzten Richtungen, bei Plinius am besten Rechnung getragen, da die Rückflut der Lagune wohl nur nach Osten oder Südosten strömen konnte. Für den größeren, etwas westlich fließenden Wasserlauf bliebe dann nur der mehrfach als ephesische Besonderheit genannte Name Kenchrios übrig, an dessen Lauf Ortygia lag; dafür gibt es aber derzeit keine ausreichenden Argumente. Die Namenszuweisung Selinus (wie auch Kenchrios) an einen bestimmten Wasserlauf muss also weiterhin offenbleiben.

Während also im Südosten der Bucht noch längere Zeit eine Lagune bestand, bildete sich seit dem 3. Jahrhundert v. Chr. nach den Erkenntnissen von H. Brückner durch die Tätigkeit des Kaystros zwischen der Syrie und dem nordwestlichen Sporn des Panayırdağ (der Spitze der Tracheia) eine Landbrücke heraus ${ }^{146}$, die bald auch die Bucht bedrohte, in der irgendwo zwischen der spätantiken Marienkirche und der hellenistischen Agora, vielleicht nahe dem großen Theater, der Hafen der von Lysimachos gegründeten Neustadt lag (Abb. 4. 14 Nr. III).

${ }^{140}$ Benndorf, Ortskunde 66-69; zuletzt werden die antiken Flussnamen völlig undifferenziert und teilweise widersprüchlich verwendet bei Kraft u. a., Analysis; Kraft u. a., Environs.

${ }^{141}$ So etwa Alzinger, Architektur 21.

${ }^{142}$ Vgl. dazu P. Scherrer, Die Fernwasserversorgung von Ephesos in der römischen Kaiserzeit. Synopse der epigraphischen Quellen, in: G. Wiplinger (Hrsg.), Cura Aquarum in Ephesus. Proceedings of the Twelfth International Congress on the History of Water Management and Hydraulic Engineering in the Mediterranean Region, Ephesus/Selçuk, Turkey, October 2-10, 2004, BABesch Suppl. 12 = SoSchrÖAI 42 (Leuven - Paris - Dudley, MA 2006) I, 45-58 bes. 53.

${ }^{143}$ Kerschner (Anm. 139) 85-226; Bammer - Muss, Artemision 27 f. (mit gegenteiliger Datierung der Böschungsmauer in mykenische Zeit). - Zur rekonstruierten Gesamtsituation des Kultplatzes auf einer kleinen Kuppe inmitten von Flussarmen bis in das 7./6. Jh. v. Chr.; vgl. Weiß1, Grundzüge, bes. 324.

${ }^{144}$ Vgl. P. Scherrer, Augustus, die Mission des Vedius Pollio und die Artemis Ephesia, ÖJh 60, 1990, 87-101; Engelmann, Kaiserkult $280 \mathrm{f}$.

${ }^{145}$ IvE 1523 f.; so auch Engelmann, Kaiserkult 281.

${ }^{146}$ Kraft u. a., Analysis, bes. $188 \mathrm{f}$. 
Schon für das Jahr 190 v. Chr. bestand nach dem Zeugnis des Livius nur eine Fahrrinne in der Breite eines Schiffes in fluminis modum longum et angustum et vaduosum zum Hafen ${ }^{147}$, woran zumindest teilweise auch mehrere hier liegende Inseln (Abb. 1. 4) schuld gewesen sein dürften ${ }^{148}$. Aber schon bald darauf versuchte der pergamenische König Attalos II Philadelphos, durch einen Damm die Verlandung des Hafens $\mathrm{zu}$ verzögern, erreichte damit aber das genaue Gegenteil ${ }^{149}$, da Ebbe und Flut nun die Flussablagerungen nicht mehr beseitigen konnten.

Genaueres lässt sich derzeit für den Stadthafen erst für die domitianisch-traianische Zeit sagen (Abb. 9-11). Spätestens damals wurde der noch heute als schilfbewachsenes Becken sichtbare, von schweren Kaimauern eingefasste Hafen an der Flanke des Bülbüldağ westlich der in unmittelbarer Folge errichteten Hafenthermen angelegt ${ }^{150}$. Hadrian ließ $129 \mathrm{n}$. Chr. einen großen Damm zum Schutz dieses Hafens gegen weitere Schäden durch den Kaystros errichten ${ }^{151}$, aber auch im Hinterland die Flussläufe regulieren ${ }^{152}$.

Nach den Funden aus archäologisch kontrollierten Tauchgängen im äußeren Teil des Hafenbeckens war der Haupthafen bis in das 6. oder 7. Jahrhundert n. Chr. benutzbar, also wohl bis zur weitgehenden Zerstörung der Stadt im zweiten Jahrzehnt des 7. Jahrhunderts. Die schlauchartige, durch teilweise noch heute sichtbare Kaimauern (Abb. 1) geschützte Einfahrt reichte im Endausbau in einer Gesamtlänge von $4 \mathrm{~km}$ bis auf wenige hundert Meter vor den heutigen Strand in Pamucak. Damit wurde der Hafen für tief gehende und größere Schiffe anscheinend unerreichbar. Kyrillos, Patriarch von Alexandria, musste bei seiner Anreise zum Konzil im Jahre 431 schon in einem Außenhafen auf ein kleineres Boot umsteigen, um damit in den alten Haupthafen zu fahren, wie auch der hl. Willibald auf seiner Pilgerreise im Jahr $723^{153}$. Willibald musste dann vom Hafen nach Hagios Theologos unum milliarium zu Fuß gehen, er landete also mit dem Boot im noch immer soweit benützbaren traianischen Hafenbecken.

Das Meer und damit die Lebensader der Stadt war von ihr gewichen. Nicht nur aus politischen Gründen musste also der letzte Versuch, hier eine hauptstädtische Siedlung auszubauen - die Tätigkeit der Aydınoğulları im 14. Jahrhundert -, scheitern. Zum letzten Mal hören wir von bedeutender Flottenaktivität in einem Hafen von Ayasoluk im Jahr 1329, als die Seldschuken zur Belagerung von Izmir aufbrachen. Nach neueren Forschungen handelt es sich dabei wohl um den bereits bei Strabon erwähnten und noch in byzantinischer Zeit verwendbaren Hafenplatz Panormos ${ }^{154}$ (Abb. $14 \mathrm{Nr}$. V), den ich ganz am Südende der Bucht von Pamucak ansetzen möchte. Hier sind im beginnenden Hang noch einige - von Geodäten der österreichischen Grabungsmannschaft 1995 vermessene und später in das Projekt zur Erforschung des seldschukischen Ephesos einbezogene - Substruktionsgewölbe, wohl ursprünglich byzantinische, vielleicht auch jüngere Hafenmagazine, erhalten ${ }^{155}$.

147 Liv. 37, $14 \mathrm{f}$.

${ }^{148}$ Vgl. die Rekonstruktion von Kraft u. a., Analysis, bes. 189 und 198 Appendix H.

149 Strab. 14, 1, 24. Kraft u. a., Analysis, bes. 189 und 198 Appendix I.

${ }^{150} \mathrm{Zu}$ den Ausbauarbeiten: IvE 2061. 3066 (beide um 100 n. Chr.). Zusammenfassend zur Quellenlage und den neueren Forschungen: H. Zabehlicky, Preliminary views of the Ephesian Harbor, in: Koester, Ephesos 201-215; H. Zabehlicky, Die Grabungen im Hafen von Ephesos 1987-1989, in: Friesinger - Krinzinger, Forschungen 479-484 bes. 482 (zum Ende der Nutzung um 600 n. Chr.).

${ }^{151}$ IvE 274; zu späteren Reinigungsarbeiten vgl. das Edikt des Proconsul Asiae Antonius Albus, IvE 23 (ca. Mitte 2. Jh.), und IvE 3071 (nach 200 n. Chr.); weitere Ausbauarbeiten durch einen Valerius Festus (3. Jh. n. Chr., wegen der Angabe einer 3. Kaiserneokorie für Ephesos im Text eventuell Zeit des Kaisers Valerianus): D. Knibbe - B. İplikçioğlu, Neue Inschriften aus Ephesos IX, ÖJh 5, 1984, 130 f.

${ }^{152}$ Knibbe - Engelmann - İplikçioğlu (Anm. 52) 122 f. Nr. 12, nennt einen 60 Fuß breiten Damm für den sonst unbekannten Fluss Manthites.

${ }^{153}$ H. Engelmann, Der ephesische Hafen in einer koptischen Erzählung, ZPE 112, 1996, 134. Zum hl. Willibald vgl. A. Bauch, Quellen zur Geschichte der Diözese Eichstätt I (Eichstätt 1962); vita Willibaldi mit deutscher Übersetzung: Monumenta Germaniae Historica Scriptores (in Folio) XV 85-106. Zu verschiedenen Lokalisierungen für den byzantinischen Außenhafen Panormos vgl. zusammenfassend Kraft u. a., Analysis 191 f. und 199 f. Diese Autoren nehmen wie bereits O. Benndorf an, dass der äußere Hafen am Ausgang des Arvalya-Tals lag (Abb. 14 Nr. IV). Wegen der viel weiter nach Westen reichenden, zweifellos spätantiken bzw. frühbyzantinischen Mauern zum Schutz der Hafenzufahrt (vgl. Abb. 1) müsste aber dieser Teil der Bucht schon im 5. oder 6. Jh. völlig verlandet gewesen sein und hätte den Stadthafen nicht ersetzen oder entlasten können.

${ }_{154}$ Strab. 14, 1, 0

155 Zur Diskussion um die byzantinischen Häfen und deren Lokalisierung, besonders des Panormos, jetzt zusammenfassend: Kraft u. a., Analysis 191 f. mit Abb. 16 (die in Rede stehenden Gewölbe befinden sich am südlichen Ende des dort mit I bezeichneten Abschnitts). 
Die Osmanen haben nach der Auflösung des seldschukischen Teilreiches im frühen 15. Jahrhundert dem Ort Ayasuluk, wie er seit der türkischen Eroberung bis in die Zeit Atatürks ${ }^{156}$ heißen sollte, keine Aufmerksamkeit geschenkt, sondern Izmir zum Zentralhafen ausgebaut. Regional aber folgte der zuerst genuesische Hafen Scala Nova als Landeplatz, von dem noch heute die auf Kreuzfahrtschiffen herbeigekommenen Touristen zur Besichtigung der ephesischen Ruinen aufbrechen.

\section{Abgekürzt zitierte Literatur}

Alzinger, Architektur $\quad$ W. Alzinger, Augusteische Architektur in Ephesos, SoSchrÖAI 16 (Wien 1974).

Bammer - Muss, Artemision A. Bammer - U. Muss, Das Artemision von Ephesos, AW Sonderh. (Mainz 1996).

Benndorf, Ortskunde $\quad$ O. Benndorf, Zur Ortskunde und Stadtgeschichte, in: FiE 1 (Wien 1906) 9-110.

Brenk, Artemis $\quad$ F. E. Brenk, Artemis of Ephesos. An Avant Garde Goddess, Kernos 11, 1998, 157-171.

Brückner, Forschungen $\quad$ H. Brückner, Geoarchäologische Forschungen in der Westtürkei - das Beispiel Ephesos, in:

T. Breuer (Hrsg.), Geographische Forschung im Mittelmeerraum und in der Neuen Welt, Passauer Schriften zur Geographie 15 (Passau 1997) 39-51.

Büyükkolanc1, Excavations M. Büyükkolanc1, Excavations on Ayasuluk Hill in Selçuk/Turkey. A Contribution to the Early History of Ephesus, in: F. Krinzinger (Hrsg.), Die Ägäis und das westliche Mittelmeer. Beziehungen und Wechselwirkungen 8. bis 5. Jh. v. Chr. Akten des Symposiums Wien 1999, AForsch $4=$ DenkschrWien 288 (Wien 2000) 39-43.

Engelmann, Topographie H. Engelmann, Beiträge zur ephesischen Topographie, ZPE 89, 1991, 275-295.

Engelmann, Kaiserkult $\quad$ H. Engelmann, Zum Kaiserkult in Ephesos, ZPE 97, 1993, 279-289.

Ephesos-Führer P. Scherrer (Hrsg.), Ephesos. Der Neue Führer (1995).

Friesinger - Krinzinger, Forschungen $\quad$ H. Friesinger - F. Krinzinger (Hrsg.), 100 Jahre Österreichische Forschungen in Ephesos, Akten des Symposions Wien 1995, AForsch 1 = DenkschrWien 260 (Wien 1999).

IvE Inschriften griechischer Städte aus Kleinasien 11, 1 (Bonn 1979) - 17, 4 (Bonn 1984) = Ephesos: IvE Ia (1979)-VIII 2 (1984).

Karwiese, Koressos $\quad$ St. Karwiese, Koressos. Ein fast vergessener Stadtteil von Ephesos, in: Pro Arte Antiqua. Festschrift Hedwig Kenner II, SoSchrÖAI 18 (Wien 1985) 241-224.

Karwiese, Artemis St. Karwiese, Groß ist die Artemis von Ephesos. Die Geschichte einer der großen Städte der Antike (Wien 1995).

Kerschner, Wanderung M. Kerschner, Die ionische Wanderung im Lichte neuer archäologischer Forschungen in Ephesos, in: E. Olshausen - H. Sonnabend (Hrsg.), »Troianer sind wir gewesen« - Migrationen in der antiken Welt, Akten des 8. Internationalen Kolloquiums zur Historischen Geographie des Altertums, Stuttgart 8.-12. Mai 2002 (Stuttgart 2006) 364-382.

Knibbe, Topographica Ephesiaca D. Knibbe, Topographica Ephesiaca. Damianosstoa, Androklosgrab - Olympieion und Koressos, ÖJh 71, 2002, 207-219.

Koester, Ephesos H. Koester (Hrsg.), Ephesos. Metropolis of Asia, Harvard Theological Studies 41 (Valley Forge 1995)

Kraft u. a., Environs $\quad$ J. C. Kraft - İ. Kayan - H. Brückner, The Geological and Paleogeographical Environs of the Artemision, in: Muss, Kosmos 123-133.

Kraft u. a., Analysis $\quad$ J. C. Kraft - İ. Kayan - H. Brückner - G. Rapp, Jr., A Geologic Analysis of Ancient Landscapes and the Harbors of Ephesus and the Artemision in Anatolia, ÖJh 69, 2000, 175-233.

Muss, Bauplastik U. Muss, Die Bauplastik des archaischen Artemisions von Ephesos, SoSchrÖAI 25 (Wien 1994 ).

Muss, Kosmos U. Muss (Hrsg.), Der Kosmos der Artemis von Ephesos, SoSchrÖAI 37 (Wien 2001).

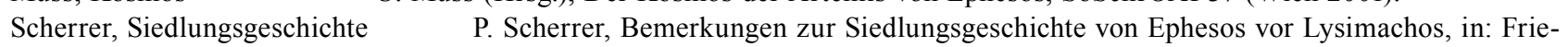
singer - Krinzinger, Forschungen 379-387.

Scherrer, Topography $\quad$ P. Scherrer, The Historical Topography of Ephesos, in: D. Parrish (Hrsg.), Urbanism in Western Asia Minor. New Studies on Aphrodisias, Ephesos, Hierapolis, Pergamon, Perge and Xanthos, 45. Suppl. JRA (Portsmouth, RI 2001) 57-93.

Scherrer, Stadttore P. Scherrer, Hellenistische und römische Stadttore in Kleinasien unter besonderer Berücksichtigung von Ephesos, in: Th. G. Schattner - F. Valdés (Hrsg.), Stadttore: Bautyp und Kunstform. Akten der Tagung in Toledo von 25.-27. September 2003, IbArch 8 (Mainz 2005) 63-78.

Scherrer - Trinkl, Agora $\quad$ P. Scherrer - E. Trinkl, Die Tetragonos Agora in Ephesos. Grabungsergebnisse von archaischer bis in byzantinische Zeit - ein Überblick. Befunde und Funde klassischer Zeit. Mit Beiträgen von S. Fabrizii-Reuer, G. Forstenpointner, A. Galik, A. Giuliani, H. Mommsen, M. Kerschner, B. Kratz-

\footnotetext{
${ }^{156}$ Der Ortsname Selçuk wurde erst unter Atatürk als Erinnerung an die seldschukische Dynastie der Aydınoğulları geschaffen.
} 
müller, M. Lawall, A. Schwedt, F. Soykal-Alanyalı, H. Taeuber, G. Weissengruber, FiE 13, 2 (Wien 2006).

Scherrer u. a., Steine

Weiß1, Grundzüge

Weiß1, Kontextualisierung
P. Scherrer - H. Taeuber - H. Thür (Hrsg.), Steine und Wege. Festschrift Dieter Knibbe, SoSchrÖAI 32 (Wien 1999).

M. Weiß1, Grundzüge der Bau- und Schichtenfolge im Artemision von Ephesos, ÖJh 71, 2002, 313-346.

M. Weiß1, Kontextualisierung im Artemision von Ephesos, Hephaistos 21/22, 2003/2004, 169-200.

Doz. Dr. Peter Scherrer

Österreichisches Archäologisches Institut, Franz Klein-Gasse 1, A-1190 Wien

E-Mail: peter.scherrer@oeai.at

Abbildungsnachweis: Abb. 1: Beil. zu FiE 1 (Wien 1906); Abb. 2: Plangrundlage P. Scherrer, Ausführung M. Hofbauer; Abb. 3: nach Kraft u. a., Analysis, Abb. 10; Abb. 4: nach Kraft u. a., Analysis, Abb. 19; Abb. 5. 12: Photo N. Gail, (C) ÖAI; Abb. 6: Photo A. Schiffleitner, (C) ÖAI; Abb. 7: F. Krinzinger, (C ÖAI; Abb. 8: Photo P. Scherrer, (C ÖAI; Abb. 9: Fatma \& Orhan Durgut; Abb. 10: Photomontage N. Gail nach Fatma \& Orhan Durgut; Abb. 11: (C) ÖAI; Abb. 13: nach H. Brückner; Abb. 14: Photomontage N. Gail, (C) ÖAI. 
